\title{
The effect of an academic dismissal policy on dropout, graduation rates and student satisfaction. Evidence from the Netherlands ${ }^{1}$
}

\author{
Eline Sneyers ${ }^{1}$ and Kristof De Witte ${ }^{1,2}$ \\ 1. Top Institute for Evidence-Based Education Research, Maastricht University, the Netherlands \\ 2. Faculty of Business and Economics, KU Leuven, Belgium
}

April, 2014

\begin{abstract}
This paper examines the effect of the introduction of an academic dismissal (AD) policy (i.e. an intervention which can lead to compulsory student withdrawal) on student dropout, student graduation rates and satisfaction with the study program. Using a Difference-in-Differences type of estimator, we compare programs that introduced an $\mathrm{AD}$ policy with a control group of programs which did not employ an AD policy. The robustness of the results is tested by a propensity score matching. The outcomes suggest that the implementation of an academic dismissal policy results in a higher first year dropout rate, and a higher student graduation rate. The results also indicate that, on average, student satisfaction decreases due to the introduction of an $\mathrm{AD}$ policy, while student satisfaction regarding program feasibility increases when an AD policy is employed.
\end{abstract}

JEL-Classification: $\quad \mathrm{I} 21 ; \mathrm{I} 22$

Key words: $\quad$ Higher education; Admission policy; Compulsory student withdrawal; Student satisfaction; School dropout; Student graduation.

\section{Introduction}

Since the 1990s, governments' interest in performance based funding has increased (Burke \& Serban, 1997; Jongbloed \& Koelman, 1996). By introducing some form of performance-based funding (PBF), many national authorities aim at pressuring higher education institutions to become more accountable, more efficient and more productive in the use of public resources (Alexander, 2000). To reflect the

\footnotetext{
${ }^{1}$ The authors would like to thank participants from the 2013 TIER lunch seminars, Studiekeuze123 seminar, seminar at the Dutch Ministry of Education, Wim Groot, Henriëtte Maassen van den Brink, Ivo Arnold, Don Westerheijden, Tommaso Agasisti, Kees Boele, Sofie Cabus, Joris Ghysels, and Chris Van Klaveren for their useful comments on previous versions of this article. We gratefully acknowledge the data support received by Studiekeuze123, especially by Bram Enning and Constance Dutmer.
} 
many dimensions of the outputs of higher education institutes in terms of quantity and quality, most PBF mechanisms use a number of different indicators, including the number of credits accumulated by students, the number of degrees awarded, or the number of research publications (Jongbloed \& Vossensteyn, 2001). The PBF mechanism provides several related challenges to higher education institutions. We focus on three major ones, while ignoring others (e.g., keeping and improving quality standards; improving research performance).

First, stakeholders of higher education institutes are increasingly focusing on student graduation rates as it is considered as a measure of institutional effectiveness (Fike \& Fike, 2008). ${ }^{2}$ Since the introduction of cost-sharing, parents and students benefit from students who graduate 'on time' as no extra tuition has to be paid (Johnstone, 2004). Because of the implementation of PBF, higher education institutes also benefit from graduation within the nominal study time, as graduation will lead to higher and sooner funding.

Second, higher education institutions put more emphasis on student satisfaction. Evidence indicates that dissatisfied students often become dropouts (Bryant, 2006). Moreover, it has been argued that students prefer to enroll in institutions with high perceived student satisfaction. Therefore, many institutions are investing in measures that increase student satisfaction (e.g., mentoring and coaching, sports facilities, study choice centrums; Bettinger and Baker, 2011). Other advantages of high student satisfaction, as indicated by Miller (2003), are high retention and graduation rates, low loan default rates and increased alumni giving.

Third, higher education institutes became increasingly selective in accepting students as they are held accountable for the relative efficiency in awarding diplomas. Current practices fall apart in two mechanisms. There is selection 'at the gate' which accepts only students with a high possibility of successfully obtaining the degree within the study period (Beller, 2001; Salvatori, 2001). Examples of such selection mechanisms include the use of the Scholastic Assessment Test (SAT) score and/or selection interviews. Next, there is selection 'after the gate', which allows all students to enroll in the first year of study. However, it has some strict rules on who can continue in or after the first year (Duijndam \& Scheepers, 2009; Lindo et al., 2010). Examples of these screening tools include the use of first-year credits (ECTs) and first-year grade point averages (GPA).

In the Netherlands, $7 \%$ of the total higher education budget is reserved for performance agreements between the government higher education institutions (both universities and higher vocational education). The main indicators of these agreements are dropout and completion rates. Due to the performance agreements many institutions decided to introduce an 'academic dismissal' (AD) policy. This intervention is based on a law of 1993 which obliged higher education institutions to provide first-year students with an advice regarding the continuation of their studies. Since 1997, some institutions have chosen to make this advice obligatory and to expel students who did not reach a predetermined credit threshold from the study program and the institution. Due to the performance agreements and the increased attention towards graduation and dropout rates, the popularity of the AD policy has increased rapidly the last couple of years.

This paper contributes to the literature in three ways. First, while selection 'after the gate' is growing in popularity (e.g., in The Netherlands, Canada, US), little is known about its effects on student dropout, graduation rates and student satisfaction (see Lindo et al., 2010; Van Heerden, 2013). This paper is the first to test the following research hypothesis:

\footnotetext{
${ }^{2}$ We use the terms 'success' and 'graduation' interchangeably throughout the paper.
} 
The introduction of an academic dismissal $(A D)$ policy results in higher first year student dropout, increased graduation rates and a decrease in student satisfaction.

As a second contribution, earlier literature on the influence of student selection mainly uses descriptive and correlational methodologies (e.g, Leverett-Main, 2004; Arnold and van den Brink, 2010; Moore et al., 2009). Unfortunately, if a proper control group is lacking, one cannot obtain causal evidence. This paper exploits the rich panel structure of the data and identifies the effect of an academic dismissal policy by a difference-in-differences (DiD) type of estimator. The estimator examines the effect of a treatment by comparing the treatment group after treatment against the treatment group before treatment and against a control group. To test the robustness of the results, we also use propensity score matching.

As a third contribution, we focus on the Netherlands for which we have a rich data set at program level (also denoted by academic degree). The Netherlands make an interesting case study for two reasons. Performance indicators as student dropout, student graduation rates and student satisfaction are measured in a nation-wide standardized way, which limits measurement errors and results in uniform data across institutions and academic degrees.

The remainder of this paper unfolds as follows. Section 2 presents the Dutch setting. In Section 3, we outline the literature review on student selection mechanisms, student dropout, student graduation, and student satisfaction. A next section discusses the identification strategy, the assumptions behind the methodology and the data. Section 5 presents the results, which are followed by robustness tests. We conclude the paper with policy advice.

\section{Setting}

\subsection{The Dutch higher education system}

Dutch higher education is organized as a binary system and consists of governmental funded and private funded institutes. Approximately $88 \%$ of the students attend a governmental funded institution (Jongbloed et al., 2004). This paper focusses only on the group of institutions with governmental funding, which consists of 17 universities and 39 institutes for higher vocational education. In addition, the Open University provides higher education through distance learning. While the universities prepare students for independent scientific work in an academic or professional setting, higher vocational institutes prepare students for the practice of a profession. Approximately one-third of the higher education students enroll in universities, while two-thirds enroll in the higher vocation institutes (Huisman, 2008). By following specific tracks in secondary education, Dutch students are sorted for continuing education and prepared for specific disciplines (De Koning et al., 2014). Admission to universities is open to students who have a certificate of pre-university education or a first-year certificate from a vocational higher education institute. Students who hold a certificate of senior general secondary education, secondary vocational education or pre-university education can enter higher vocational institutes (Huisman, 2008).

As of 2002, Dutch higher education institutes offer programs of 60 credit points per year in accordance to the European Credit Transfer System (ECTS). Credit points measure the workload or 'study time' that is required to complete a course or program. In the Netherlands, as in most European countries, a norm for a credit point is a workload of 28 hours, meaning that a program year consists of 1680 hours of work a year. The workload of students consists of the hours in classes and the hours needed to prepare for classes, exams and other forms of assessments.

\subsection{Academic dismissal policy}


In the Netherlands, universities and higher vocational institutes are legally obliged to provide each student with an advice on the continuation of their studies by the end of the first year of enrollment (Law on Higher Education and Scientific Research, art. 7.8b). Based on this law, higher vocational institutions can issue obligatory (binding) advice to students (Onderwijs Evaluatie Rapport, 2007). Issuing obligatory (binding) advice can be seen as an AD policy (in Dutch 'Bindend Studie Advies'). Whether a binding advice is positive or negative depends on the number of study credit points ${ }^{3}$ obtained by the student during the first year. Every course that students follow is linked to a number of credits, depending on the workload. When students pass the course, they earn the corresponding credits. Students who do not earn a sufficient number of credits to reach the threshold, and thus make substandard progress after the first year, are dismissed. The credit-threshold students must pass is decided by each institution and can vary by program, and type of higher education (De Koning et al., 2014). On average, the standard is $41 \mathrm{ECs}$ in higher vocational education, whereas the credit-norm is 38 ECs at universities (Inspectie van het onderwijs, 2010). Before an AD policy is issued, students receive an academic warning, hereby giving them a wake-up call and a chance to improve their performance (Rijksoverheid, n.d.). When academic dismissal is issued it leads to the termination of the student's enrolment for the current program. Further, dismissed students cannot register for the same study program for a certain period, often three years (De Koning et al., 2014). During the academic year 2007/2008, the vocational institutes issued more than 14,000 academic warnings, while in the scientific education over 3,900 academic warnings were given (Inspectie van het onderwijs, 2010).

By using an AD policy, two objectives are pursued. First, it helps students to learn at an early stage whether the program fits them. Second, it allows programs to select and continue with the most talented and motived students after the first year (De Koning et al., 2014). Because the AD policy is in line with the orienting, selecting and referential function of the propaedeutic phase in higher education, it is used in many universities and vocational institutes (Onderwijsraad, 2008).

While non-obligatory study warnings are a tradition in Dutch higher education, the use of AD policies increased considerably in the last few years. In 1997, only one university had implemented an AD policy (Onderwijs Evaluatie Rapport, 2007). In 2000, 67\% of all vocational study programs made use of an $\mathrm{AD}$ policy against $10 \%$ of the study programs at university level. Due to the increased attention towards the increase of graduation rates and the decrease of dropout more institutions started to implement AD policies. Moreover, 98\% of the study programs at vocational level and $43 \%$ of the study programs at university level had an AD policy against 2007. These study programs were localized at 40 higher vocational institutions and seven universities. At university level, the use of an $\mathrm{AD}$ policy is most common in the study fields Economics, Law, Linguistics \& Culture, and Behavioral \& Social Sciences. The interest concerning the use of an AD policy is still increasing (Inspectie van het onderwijs, 2010). This process is represented in figure 1 which shows the percentage of programs with an $\mathrm{AD}$ policy ${ }^{4}$. We observe a steep increase in the use of AD policies between the academic years 2006-07 and 2008-09. During this time period, an extra 10\% of the programs decided to implement an $\mathrm{AD}$ policy. Figure 2 presents the number of programs per credit

\footnotetext{
${ }^{3}$ Note that the performance requirements of the AD policy also can be qualitative, such as passing essential courses (Mennen, 2013). However we will not focus on this type of AD policy, as it is difficult to measure and interpret this kind of performance requirements.

${ }^{4}$ Both figures make use of information extracted from our data. Since we only have information as of 2003, we are not able to provide a visual representation of the implementation process and the use of credit thresholds before 2003.
} 
threshold. We observe that the majority of the credit threshold is 36-40 ECTS, followed by 41-45 ECTS. There is also a tendency towards higher thresholds.

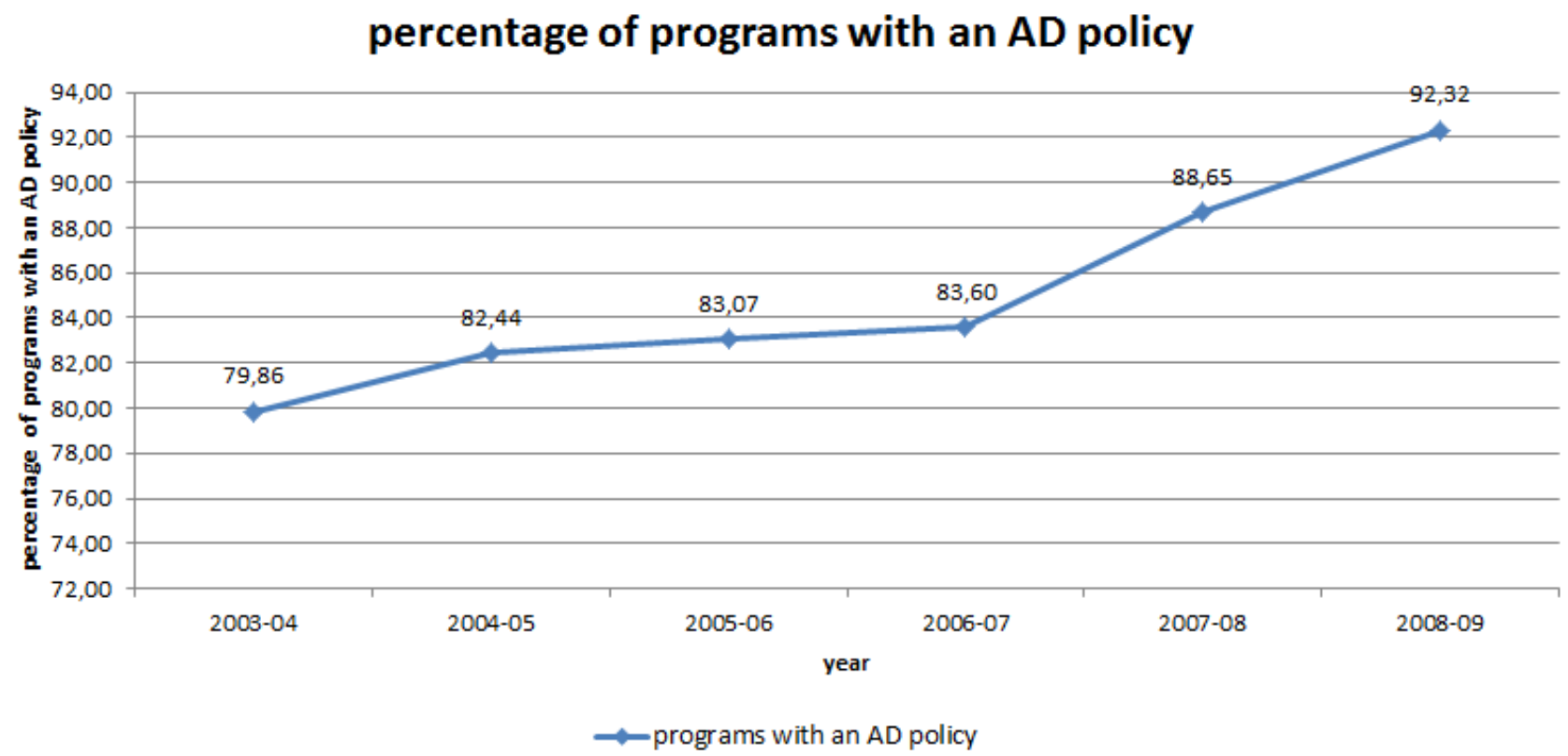

Figure 1: Percentage of academic programs with an AD policy per year

\section{The number of programs per credit threshold}

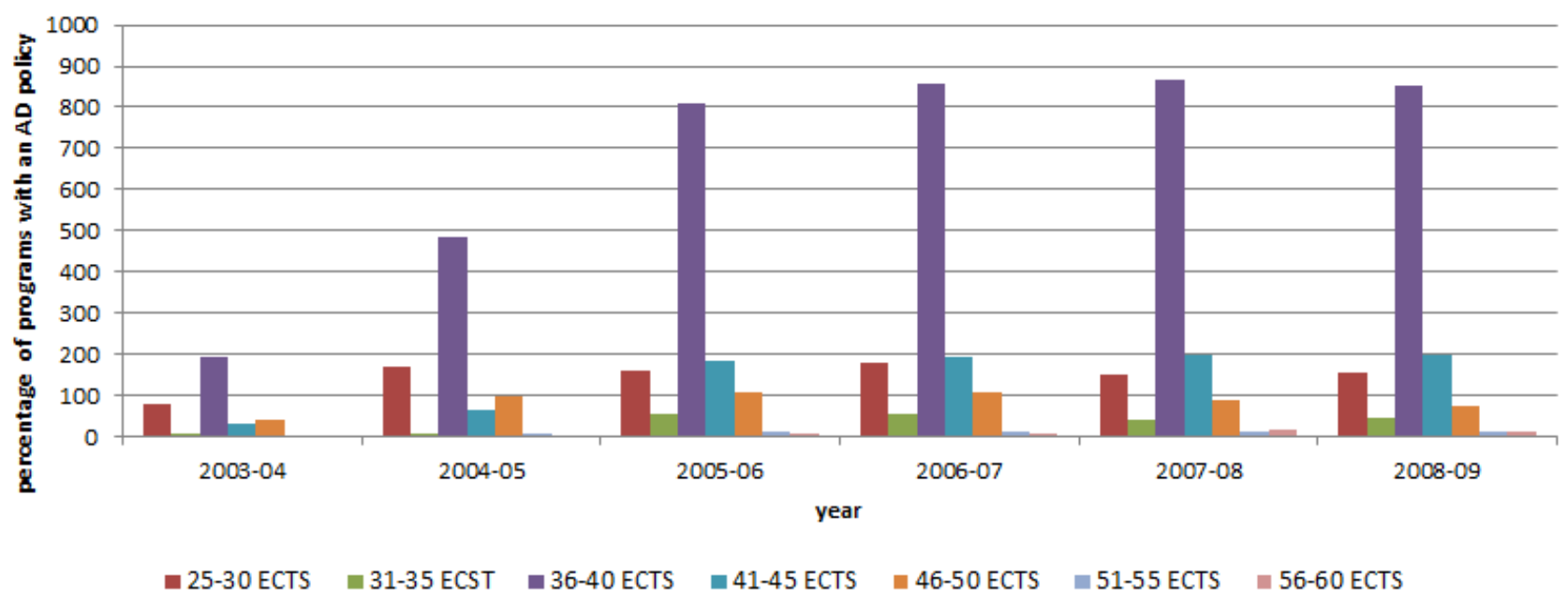

Figure 2: The number of programs per credit threshold per year

\section{Literature Review}

Higher education institutions are increasingly held accountable for their students (Huisman \& Currie, 2004). In some countries, financial agreements between the government and higher education institutions even include targets on student dropout, student graduation and student satisfaction (in Australia, the Netherlands, Hong Kong) (OCW, 2011; Benneworth et al., 2011). We review the literature on student performance indicators and student satisfaction. 


\subsection{Student performance indicators.}

\subsubsection{Student dropout and student graduation}

Different studies show that high freshman attrition rates go hand in hand with a higher percentage of students graduating on time (e.g., Lau, 2003; Levitz et al., 1999). As a result, institutions try to stimulate graduation rates by keeping first-to-second-year dropout under control. The student integration model of Tinto $(1975,1993)$ and the student attrition model of Bean (1990) conceptualize the dropout phenomenon. These conceptual models acknowledge the important role of organizational factors and the commitment to the institution. Furthermore, there is a wide variation of dropout rates within groups of similar institutions which suggests that institutions can control their dropout rates (first noted by Forrest, 1982). Not surprisingly there exists an extensive body of research that identifies the conditions in which institutions should place their students in order to promote student retention and student graduation ${ }^{5}$.

First, student/staff ratios are positively correlated with dropout rates (e.g., Scott et al., 2008) and negatively with graduation rates (Bound et al., 2010). Indeed, a low student/staff ratio will lead to frequent interaction between student and staff which in turn will lead to student academic integration and persistence (Tinto, 2002). Next, differences in student success and student dropout can be due to differences in institutional size. Most studies (e.g., Calcagno et al, 2008) find a negative relationship between institutional size and individual success. Chickering and Reisser (1993) offer one explanation as to why student outcomes are negatively affected by institutional size. Moreover, if the institution increases in size, the amount of students increases faster than the number of settings such that the ratio of people to settings increases. Consequently, social and academic support suffers. Conversely, Titus (2004) finds that the average chance of dropout can be decreased by four percent by a one standard deviation increase in institutional size.

Besides institutional structures, student characteristics can also influence educational outcomes. Research finds mixed results regarding the influence of gender on dropout and student achievement. Several studies (e.g., Scott et al., 2006; Peltier et al., 1999) find that gender is significantly related to student dropout and graduation. Peltier et al. (1999) conclude that women are less likely to dropout than men. In the same vein, Porter (2000) and Scott et al. (2006) indicate that vocational institutions that are more female are expected to have higher graduation rates. These gender differences in degree performance may be the result of differences (i) in psychological and/or biological factors and (ii) in characteristics that are correlated with attainment (e.g. family background), (McNabb, 2002; Mellanby et al., 2000). Nevertheless, Reason (2003) fails to find a significant relationship between dropout and gender. Bailey et al. (2006), on the other hand, find a negative relationship between the percentage of female students and graduation rates. The class level of students can also influence the dropout process. The class level (graduate or undergraduate) is based on the number of credit hours a student has earned, and hence the study year the student is enrolled at. Bean and Bradley (1986) claim that class level has a positive impact on performance. This finding is in line with a more recent study which finds that cumulative GPA is negatively related to dropout (Okun, 1998). Adelman (2006) also shows that the cumulative credits and GPA are negatively associated with dropout and positively linked to graduation. The above findings can be attributed to the fact that students learn how to get better grades as they progress through their educational careers. Finally, academic effort, measured by study skills, also predict student dropout

\footnotetext{
${ }^{5}$ Note that graduation and dropout are complex concepts which are influenced by other factors than discussed above. Because we want to keep the literature section to the point we only discuss the factors we used in our study.
} 
and student graduation. Pantages and Creedon (1978) find that students with poor study habits have a higher likelihood of becoming a dropout. It is also shown that students who participated in a study skills course acquired higher grades than predicted by their previous academic performance (Cone \& Owens, 1991). In a similar vein, more recent studies (e.g. Hughes \& Pace, 2003; Kuh et al., 2008 ; Chambers, 2009) show that student engagement, as a proxy of student effort, is negatively related to dropout.

\subsubsection{AD policy as a form of selection after the gate}

Due to the increased accountability towards their students and the financial agreements which are often in place, institutions try to improve the earlier discussed performance indicators. Many institutions focus on interventions aimed at first-year students since Levitz et al. (1999) noted that this is the most crucial period for students. Some institutions try to achieve this by introducing more selective admission standards, which reduce the number of applicants, and make a distinction between the students who are likely to succeed and the students who are likely to dropout (Duncan-Hewitt, 1996; Hagedorn \& Nora, 1996; Beecher \& Fischer, 1999). Cox et al. (2005) indicate that more selective admission standards have been related to higher retention rates. While in the past admission standards often had a focus 'at' the gate, today admission standards 'after' the gate are becoming increasingly popular.

Selection 'after the gate' denotes performance based mechanisms to remove students making unsatisfactory academic progress from the institution. Performance based selection systems have a general structure. If a student's performance falls below the minimum standards of the enrolled institution, the student gets a warning which serves as a wake-up call and can lead to escalating penalties. Ideally, selection 'after the gate' should happen in the first year as Yorke and Longden (2004) call this a critically important period for the connection between students and their programs. Bénabou and Tirole (2003) argue that the impact of performance standards on students differs by the type of students. Setting performance standards can motivate some students to improve their performance while others can be discouraged from making any attempt at all.

In the Netherlands, many universities and vocational institutes implemented such system in the form of an AD policy (Van Heerden, 2013). This system requires students to make satisfactory study progress during their first year (see section 2.2). Studies find mixed results concerning the influence of AD policies on dropout and graduation. Duijndam and Scheepers (2009) indicate that the introduction of an $\mathrm{AD}$ policy in a business management program resulted in earlier students' withdrawal in the first year, compared to programs where no AD policy is in use. This shows that fewer students linger in the program because of the introduction of a credit threshold. According to Gijbels et al. (2004) an AD policy is an effective tool for the identification of well-performing students. By comparing two cohorts of students (one in which an AD policy was implemented and one in which this was implemented fictitiously) evidence was found that students who would have been dismissed, if their institute applied a credit threshold, obtained lower numbers of credits in their second year. Also a lower first-year completion rate was found. Next, Arnold (2014) compared bachelor programs between the academic years 2002-03 and 2007-08. During these years some programs implemented an AD policy (i.e. intervention group) while others did not (i.e. control group). He proves that the introduction of an AD policy increased the first-year dropout rate and the 4-year completion rate of university students. Another study shows that an increase in credit threshold leads to an increase of student success (Task force studiesucces, 2009). Nevertheless, Stegers-Jager et al. (2011) observe that the presence of an AD policy did not lead to early dropout or higher completion rates during the first two years at medical school. Further, Arnold and Van de Brink (2010) claim that 
the number of students languishing in scientific education will not necessarily be reduced by the introduction of a credit-threshold because students who are dismissed often do not get any help in selecting a new program, resulting in a poor performance in their next program. Finally, it is shown that while the introduction of a credit threshold leads to a positive change in study behavior, this introduction does not necessarily translate into a higher level of performance. This may indicate that students rather try to reach the credit requirements than acquiring as much knowledge as possible (De Koning et al., 2014).

\subsection{Student satisfaction}

As students nowadays are more "consumer oriented" and as higher education institutions are rewarded through performance-based funding, student satisfaction becomes increasingly important. Students who do not feel satisfied by their institution of choice, due to a mismatch between student expectations and institutional performance, have a high risk of dropping-out or transferring to another institution. Moreover, student satisfaction has a positive influence on student motivation, student retention, recruiting efforts and fundraising (Schertzer \& Schertzer, 2004).

Student satisfaction is a highly complex concept, influenced by various observed and unobserved factors. It is influenced by all experiences related to campus life, and not only to what happens to them in the classroom. However, universities and vocational institutes typically focus on the academic dimension of a student's educational experience (e.g., student-to-faculty ratios and quality programs) (Elliott \& Shin, 2002). As a consequence, Kotler and Fox (1995) observe that while students are, on average, highly satisfied with their academic programs, their satisfaction with the support services is low. We identify a number of institutional and student characteristics which literature argued to affect satisfaction.

First, it seems that a substantive relationship with faculty or staff affects students' satisfaction by deepening institutional connections and commitment (Peterson et al., 2001). Elliott (2002) indicates that faculty accessibility increases student satisfaction and positive feelings about college. Next, Wiers-Jenssen et al. (2002) observe that while students in universities and large state colleges are less satisfied, students at university colleges are more satisfied. They argue that the reason for this result is two-fold. First, the institutional size can have an independent influence on student satisfaction. Second, universities and large state colleges may be more research-oriented than smaller higher education institutes, resulting in research drift of staff (Dill, 2001) and a lower focus on teaching-activities which might result in lower satisfaction (De Witte et al., 2013). Third, male-female differences result into significant differences in satisfaction with college (Adelman, 1991; Rienzi et al., 1993). Most studies find that woman report lower levels of satisfaction with college compared to men. However, Umbach and Porter (2002) report that the proportion of female undergraduates in a department is highly correlated with satisfaction concerning education in the major and with personal skill development. The class level (graduate of undergraduate) can also influence satisfaction. Tan and Kek (2004) find mixed results concerning satisfaction with service quality and class level. While at university A graduates perceived a higher level of service quality in comparison to undergraduates, the opposite was true in university B. Finally, Krohn and O'Conner (2005) suggest that academic effort has a positive association with satisfaction. The effort devoted to a course or program may produce satisfaction directly if students find the activity of studying satisfying on itself. In addition, the results of that effort, e.g. knowledge and grades, may lead to satisfaction. 
The combination of increased institutional accountability, performance agreements with student satisfaction as target and the increased use of $\mathrm{AD}$ policies, makes it important to know what will happen to student satisfaction. However, this relationship has not yet been empirically investigated. One Dutch descriptive study (Onderwijs Evaluatie Rapport, 2007) mentions that students judge the AD policy as something positive. However, students who obtained almost all first-term credits found it a more positive measure in comparison to students who obtained a limited number of first-term credits. These findings tend towards an increase of student satisfaction since students who obtained a high number of credits are likely to be retained by the AD policy.

\section{Identification strategy, data and assumptions \\ 4.1 Identification strategy}

To estimate the influence of the introduction of an $\mathrm{AD}$ policy on student dropout, graduation and satisfaction, we apply a difference-in-differences (DiD) type of estimator. It is one of the most popular tools to evaluate the effect of interventions on some relevant outcome variables (Abadie, 2005). Although we claim that $\mathrm{AD}$ policies are introduced in a rather exogenous way (see section 4.2), we have to account for the time trend as the control and intervention group in this study are not identified at the same time but in a different chronological academic year. A chronological time trend can lead to a biased estimate of the effect of introducing an AD policy. The DiD approach accounts for this time trend by including an extra control group of academic programs which will never implement an AD policy. Moreover, the traditional DiD examines the effect of a treatment by comparing the treatment group after treatment against the treatment group before treatment and against a control group. The outcome $\mathrm{Y}$ for study program $i$ is traditionally modeled by the following equation:

$$
Y_{i}=\alpha+\beta D_{i}+\gamma t_{i}+\delta\left(D_{i} \cdot t_{i}\right)+\varepsilon_{i}
$$

where the $\alpha$ denotes a constant term, $\beta$ the treatment group ( $D=1$ : treatment) specific effect, $\gamma$ is the estimated coefficient for the time trend ( $t=0$ : pre-treatment, $\mathrm{t}=1$ : post-treatment) common to control and treatment group, $\delta$ stands for the variable of interest as it estimates the effect of the treatment, and $\varepsilon_{\mathrm{i}}$ is an error term. As revealed by the interaction effect, the DiD estimator is defined as the difference in average outcome in the treatment group before and after the treatment minus the difference in average outcome in the control group before and after treatment (Albouy, 2004):

$$
\hat{\delta}_{D i D}=\bar{Y}_{1}^{T}-\bar{Y}_{0}^{T}-\left(\bar{Y}_{1}^{C}-\bar{Y}_{0}^{C}\right)
$$

In typical $\mathrm{DiD}$ estimations the treatment is a one-time change in policy equally applied to all members of the treatment group. Due to the equal application, the treatment and control groups can be identified. Because it is a one-time change, specific pre- and post-treatment points in time can easily be selected. Our study tends to differ from the typical treatment in one important way. AD policies have not been one-time events but have been implemented gradually over multiple years. Taking this issue in consideration, we apply the following model:

$$
Y_{i}=\alpha+\beta\left(D_{i}\right)+\gamma \sum_{t} t+\delta A D \_p o l i c y_{i t}+\mu X_{i t}+\varepsilon_{i t}
$$

where $t_{t}$ is a dummy variable for each year (from 2003-04 until 2008-09, where 2003-04 is the reference year) and $\mathrm{D}_{\mathrm{i}}$ a dummy variable that assumes 1 for all programs which eventually applied an $\mathrm{AD}$ policy and else 0 . The model is completed by the AD policy intervention dummy, a categorical interaction variable that is 1 for programs after the start of an AD policy and 0 else (see table 1). We further add additional time ( $\mathrm{t}$ ) and program (i) specific control variables $\mathrm{X}$. This increases the efficiency and consistency of the variables of interest. Note that in the suggested identification 
strategy, the control group consists of all study programs which have never implemented an AD policy, whereas the treatment group is created from all study programs which eventually have implemented a study program. We discuss and test the assumptions behind this identification strategy in Section 4.2.

Table 1: Schematic presentation of the identification strategy

\begin{tabular}{ccc}
\hline & Control group & Treatment group \\
\hline $\begin{array}{c}\text { Before } \\
\text { implementation AD policy } \\
\begin{array}{c}\text { After implementation } \\
\text { AD policy }\end{array}\end{array}$ & $\mathrm{d}=0 ; \mathrm{t}=0$ & $\mathrm{~d}=1 ; \mathrm{t}=0$ \\
& $\mathrm{~d}=0 ; \mathrm{t}=1$ & $\mathrm{~d}=1 ; \mathrm{t}=1$ \\
\hline
\end{tabular}

Figure 3 presents the identification strategy graphically. The horizontal axis represents the time and the vertical axis the outcome variable. The upper curve represents the outcome variables of the control group, and the lower curve represents the outcome variables of the treatment group. The dashed line indicates the implementation of the $\mathrm{AD}$ policy at a certain moment in time, while the arrow measures the difference in outcome variables caused by the treatment (i.e., the difference between the observed and counterfactual outcome). The figure illustrates that our analyses take three different effects into account: the 'period/cohort' specific effects, the 'treatment group' specific effects and the effects due to the implementation of an AD policy. Including the 'treatment group' specific effects is important as academic degrees which implement an AD policy might have different (un)observed characteristics than academic degrees without an AD policy (see section 4.3 for an extensive discussion).

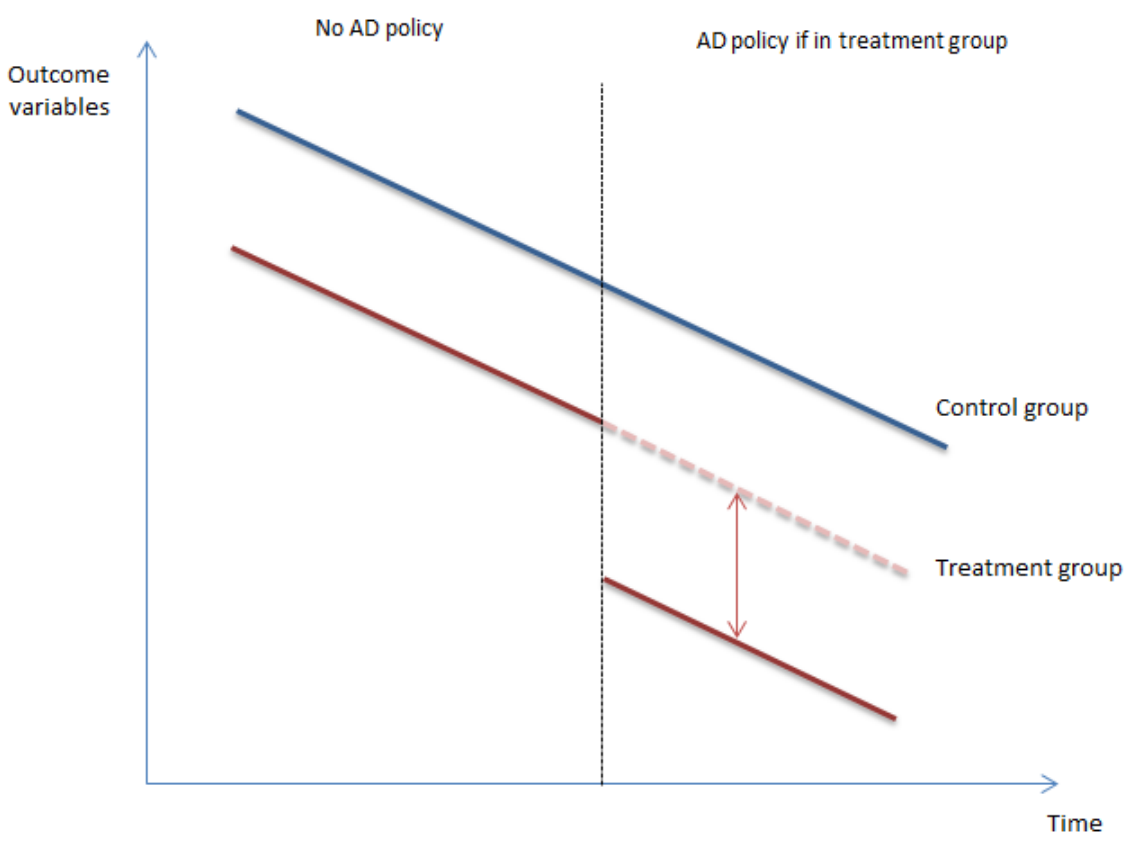

Figure 3: Visual representation of the identification strategy

\subsection{Assumptions behind the identification strategy}

The identification strategy relies on some assumptions, which we discuss and test next. 
First, the control group should be a well comparable group for the treatment group. We test this assumption by checking whether characteristics of the control and intervention group differ significantly (see section 4.3). Since some of the characteristics are significantly different, we cope with this issue in two ways. First, we include the variables as control variables in the regression analysis such that existing heterogeneity among the control and treatment group is absorbed. Second, as a robustness test, we use a propensity score matching to select a well comparable control group. The matching results (see section 6.1) confirm the robust outcomes.

As a second assumption, the 'common trend assumption' argues that, before the implementation of an AD policy, the trend of the observed and unobserved variables between the group of programs that eventually will implement an $\mathrm{AD}$ policy and the control group should be similar. We test the assumption by examining whether the difference between the two described groups changes significantly between two subsequent years in the period before the introduction of an $\mathrm{AD}$ policy. The results indicate that the common trend assumption is met for all years for the variables student dropout and student graduation (Appendix A, Table 1-3). The results for the variables concerning satisfaction show that the assumption is not always met. Specifically for the subsequent years 2003-04 and 2004-06, and 2005-06 and 2006-07. Consequently, observations for those years will be included in a second robustness check (see section 6.2). The above results may be explained by the fact that student satisfaction can rapidly change due to changes in the educational environment (Elliott \& Shin, 2002). Student dropout and graduation do not respond as quickly.

The 'Stable Unit Variance Assumption' (STUVA) requires that the outcomes are not influenced between the control and treatment group. The common perception that an AD-policy is implemented institution-wide is wrong. Often programs in the same institution decide individually whether they implement an AD policy. Students who follow different programs and who are at different faculties or even at different institutions have little possibilities to interact and influence each other. Students who received a negative AD and decided to follow a new program at a different institution are able to influence the opinions of their new peers. However, we do not expect that this situation will reshape the perceptions of the fellow students drastically.

Fourth, the AD policy should be introduced in a rather exogenous way. Proving that the AD policy is introduced exogenously would require qualitative evidence, which is beyond the scope of this paper. Nevertheless, from the annual reports we know that the introduction and strengthening of an AD policy does not depend on certain institutional or program characteristics. Moreover, we can test the correlation between the introduction of an $\mathrm{AD}$ policy and program and/or institutional characteristics such as quality and the number of students. To have an indication on the program quality, we make use of the accreditations of the Dutch-Flemish Accreditation Organization (NVAO). The NVAO is an independent agency, founded by the Dutch and Flemish (i.e., the Dutch speaking region of Belgium) government to assess the quality of higher education. To test for potential correlation between program quality and program admission criteria, we estimate an institution fixed effect model with the introduction of AD policy as dependent variable, and various quality indicators as independent variables. The fixed effect regression mitigates the influence of institution fixed variation. The results, presented in Table 2, indicate that the introduction of an AD policy does not correlate to the quality of an institution. In a second model we include the institutional characteristics student enrollment and student-staff ratio to account for fast growing institutions (Table 4). The results indicate that the variable $A D$ policy is independent of the student-staff ratio. However, the variable $A D$ policy depends on the number of students enrolled. This indicates that when an institution knows a sudden growth of students, it often introduces an AD policy. To control for the influence of the student enrollments, we add this variable to the further analyses. 
Given that we fulfill the above conditions, we are able to estimate the average treatment effect of the treated (ATT). Specifically, ATT is the average effect on student dropout, student graduation, and student satisfaction caused by to the introduction of an $\mathrm{AD}$ policy. In figure 3, this effect is presented by the dashed arrow (see section 4.1).

Table 2: Institution fixed effect model with the variable "AD policy" as outcome variable.

\begin{tabular}{lcccc}
\hline Variable & \multicolumn{2}{c}{ Model 1 } & \multicolumn{2}{c}{ Model 2 } \\
& Coef. & SE & Coef. & SE \\
\hline Constant & $.848^{* * *}$ & .019 & $.520 * * *$ & .093 \\
Quality indicators (NVAO-data): & & & & \\
- Program requirements & -.001 & .012 & .001 & .012 \\
- Staff requirements & -.019 & .012 & -.020 & .012 \\
- Improvement measurements & -.003 & .012 & -.004 & .012 \\
- Achieved level & .004 & .008 & .004 & .008 \\
Student enrollment & & & $.000 * * *$ & .000 \\
Student-staff ratio & & & -.002 & .003 \\
\hline Number of observations & \multicolumn{2}{c}{1,978} & \multicolumn{2}{c}{1,962} \\
Number of groups (fixed effects at & \multicolumn{2}{c}{40} \\
institution level) & \multicolumn{2}{c}{40} \\
\hline Where & & & \\
\hline
\end{tabular}

Where $* * *, * *$, and $*$ denote, respectively, significance at 1,5 and $10 \%$-level.

\subsection{Data and descriptive statistics}

\subsubsection{Data}

The data are obtained from the Dutch Ministry of Education ('Dienst Uitvoering Onderwijs', DUO). They include information at academic degree level (e.g. biology, applied linguistics) concerning the number of first-year students, the dropout rate, the number of students who re-enroll after the first year, and student graduation rates for all higher education institutes for the years 2010 and 2011. The academic degree is the set of courses that a student follows in order to obtain a degree (e.g., bachelor in economics). The data also include the above indicators on the field of study for all years between 2003 and 2011. The field of study (e.g., technique, law, nature and economics) denotes to which academic field the program belongs.

The data have two limitations, which we need to deal with. First, we lack academic degreelevel data from 2003-09. We deal with this by effectively combining the field of study data of 200309 with the program level data of 2010-11. The underlying assumption is that the trend of the indicators on program-level is similar to the trend of the indicators on field of study-level. ${ }^{6}$ This assumption holds as the final data are similar to reports by field organizations. As a second limitation, we cannot make a distinction between programs at different locations of the institution. Therefore, we exclude the programs that did not implement an AD policy simultaneously at all locations.

The output variables are defined as follows. Student dropout is defined as the percentage of full-time bachelor students that leave the institution during the first year of enrollment. Student graduation is defined as the share of re-enrolled full-time bachelor students that obtained a degree at

\footnotetext{
${ }^{6}$ When the interpolation resulted in values larger than 100 percent or smaller than zero percent for the performance variables, this value is replaced by 100 percent or zero percent respectively. Further, we excluded programs that were terminated in 2010 or 2011, since this event can influence student success and student dropout of previous years.
} 
the institution one year after the nominal study time. Consequently, in order to be included in this latter indicator, students enrolled in universities need to graduate in four years, while students enrolled at higher vocational institutes need to graduate in five years.

We also obtained academic degree level (also called program) data from the annual national questionnaire on student satisfaction ('nationale studentenenquête', NSE). The survey is carried out by the organization Studiekeuze123 and includes information on the opinion of students about the program they are taking. The data also contain institutional information (e.g., the number of students and programs in the institution) and student characteristics (e.g., the percentage of woman or the percentage of first-year students). Although the NSE is an annual survey since 1991 it was not until 1995 that the NSE was carried out on sufficient large scale. In 1995, the NSE became a questionnaire with a fixed division of student issues (Steenkamp et al., 2008b). As of 2003, the organization started to document the student outcomes of the surveys in (publicly available) digital databases (Steenkamp et al., 2008a).

The NSE data have three limitations. First, the student outcomes of the NSE were not (or just limited) registered in digital databases until 2003-04. Consequently, we do not have NSE information before 2003-04. Second, there is a break in the survey questions in 2009-10 which creates data comparability issues. Therefore, we only consider the surveys between 2003-04 and 2008-09. Third, at the time the data was collected, it was not yet possible to survey every program each year. Therefore large programs were surveyed every two years and small programs every three years (Steenkamp et al., 2008a). In order to obtain a balanced panel data set, Studiekeuze123 replaced missing data on student opinions by records from a previous year. The institutional characteristics, on the other hand, are annually adjusted.

Between January and March, students in participating programs are invited to complete the questionnaire and to give their opinion about different aspects of the program. The main purpose of the NSE, the measurement of student opinions, is evaluated by 30 items on a ten point scale ranging from (1) very dissatisfied to (10) very satisfied. These 30 items are grouped into 10 dimensions and one measure of overall satisfaction. The categories are: content of the academic degree, electives, consistency, teaching methods, career preparation, teachers, campus facilities, campus buildings, communication, and feasibility (Steenkamp et al., 2008a).

In the paper at hand, we focus on three central questions in the NSE questionnaire. First, students are asked about their overall satisfaction with the program ("Are you satisfied with your choice for this program at this institution?" $?^{7,}$. The next outcome variable focuses on a specific subject of student satisfaction, namely feasibility of the program ("Is the program feasible in the available time"). It measures whether students think they are able to complete the degree. In order to exploit the richness of the data, we construct an outcome variable (i.e., average NSE score) consisting of the average of all items surveyed in the NSE data. The latter variable has the advantage of being rather comprehensive and reducing the influence of extremely high or low items, which comes at the cost of having an imprecise interpretation (i.e., the average of all items). Note that the three outcome indicators applied in the paper are well behaved in terms of homogeneous variance and normal underlying distributions, such that parametric analyses can be applied.

Because participation to the NSE is voluntary for each individual student the threat of selection bias exists. Although we are not able to investigate the bias at the individual student level,

\footnotetext{
${ }^{7}$ In the NSE of 2007 the central question changed into "give your overall judgment about the program". An analyses of the density functions of both questions, shows that they are comparable.
} 
we do not expect selection to be a serious issue. First, response rates are comparable with the response rates of other college student surveys. From the 588,571 students addressed in 2011, 35.2 percent returned a usable NSE survey. In 2010 a similar response rate of 35.1 percent was found (Broek et al., 2012). For comparison, the National Survey of Student Engagement (NSSE) had an average institutional response rate of 30\% in 2013 (NSSE, 2013). Second, by all stakeholders (university management, program directors, civil servants, student bodies) the NSE data are generally considered as a reliable and representative instrument. Third, as illustrative evidence of its importance and reliability, the data are also used in a new performance-based scheme to finance institutions based on performance agreements.

Results of the NSE questionnaires are made public and are used for different purposes. On the one hand, the student assessments are used to maintain or improve internal quality. By analyzing the results it becomes clear which aspects already satisfy students and which aspects should be improved. On the other hand, the results are used to provide comparable information to students about the different academic programs and help them to make a good study choice. The latter is facilitated by a website and publication in influential magazines (studiekeuze123, 2012).

To obtain our final sample, we combine the DUO and NSE data. We take a few restrictions into account. First, although AD policies were first implemented in 1997 we only focus on data between the years 2003-04 and 2008-09. This is the result of the limited data availability before 2003-04 and the break in NSE survey questions in 2009-10. We also focus on state funded institutions since these institutions have to decrease student dropout and increase graduation rates and student satisfaction in order to obtain funds. Consequently, these institutions will be more likely to introduce an AD policy. Next, the sample is restricted to bachelor programs as master programs do not have an AD policy. Thus, the final sample includes all bachelor programs in state funded higher vocational and university institutions between 2003-04 and 2008- $09^{8}$. This dataset contains information about the dropout rate, the graduation rate, student satisfaction opinions, student characteristics and institutional information for each study program. The final sample includes 6,012 higher education degrees (i.e., an average of 1002 study programs per year).

\subsubsection{Descriptive statistics}

Table 3 presents descriptive statistics for the study programs with (i.e., the treated group) and without (i.e., the control group) an AD policy. We observe that there are 266 unique programs in the control group, against 1,486 unique programs in the treatment group ${ }^{9}$. The institutional characteristics indicate that programs that implemented an AD policy tend to have more students enrolled and have a higher student-staff ratio. The descriptive statistics show no significant difference concerning the percentage of woman between program with an $\mathrm{AD}$ policy and programs without an AD policy. Further, programs with an AD policy have a higher percentage of students for the second and fourth year enrolled compared to programs without an $\mathrm{AD}$ policy. However, there is no significant difference concerning the percentage of students enrolled for the third year between both groups of

\footnotetext{
${ }^{8}$ Note that since programs which already implemented an AD policy before 2003-04 do not influence the regression specification, we exclude these programs from the analysis (it should be noted that including those observations results in very comparable outcomes; available upon request).

9 Note that the total sample consists of 6,012 study programs (see section 4.3.1). For clarity, in the descriptive statistics we present only the number of unique programs. Moreover, when a study program appears every year in the data set it is considered in the descriptive statistics as one unique program while in the total sample it is counted as six observations (i.e. one for every year).
} 
programs. Finally, students in programs without an AD policy tend to study more as is indicated by the variable study time.

Table 4 presents some descriptive statistics for the different outcome variables. The descriptive statistics show that all five outcome variables differ significantly between programs with and without an $\mathrm{AD}$ policy. The statistics show that more students drop out after the first year of enrollment in programs with an AD policy compared to student in programs without an AD policy. Students in programs that implement an AD policy also have a higher graduation rate compared to students in programs that do not employ an AD policy. Students in an institution without an AD policy have, on average, a higher overall satisfaction with their program than students in institutions with an AD policy. Students in institutions with an AD policy indicate that they find the program more feasible. 
Table 3: Descriptive statistics of student characteristics and equality of means between control and treatment group

\begin{tabular}{|c|c|c|c|c|c|c|c|c|c|}
\hline Variable & $\begin{array}{l}\text { Control/treat- } \\
\text { ment group }\end{array}$ & $\begin{array}{l}\text { Number } \\
\text { of obs. }\end{array}$ & First quartile & Mean & Third quartile & Minimum & Maximum & $\begin{array}{l}\text { Standard } \\
\text { deviation }\end{array}$ & $\begin{array}{c}\text { T-test }(\mathrm{dif}=\text { mean }(0) \\
-\operatorname{mean}(1))\end{array}$ \\
\hline \multicolumn{10}{|c|}{ Institutional Characteristics } \\
\hline \multirow{2}{*}{$\begin{array}{c}\text { Number of unique } \\
\text { programs }\end{array}$} & 0 & 266 & & & & & & & \\
\hline & 1 & 1,486 & & & & & & & \\
\hline \multirow{2}{*}{ Number of students } & 0 & 812 & $17,220.00$ & $18,621.33$ & $23,794.00$ & 990.00 & $29,524.00$ & $6,742.82$ & \multirow{2}{*}{$-3,551.43 * * *$} \\
\hline & 1 & 5,200 & $15,298.00$ & $22,172.76$ & $32.074,00$ & 281.00 & $38,551.00$ & $10,686.20$ & \\
\hline \multirow{2}{*}{ Student-staff ratio } & 0 & 812 & 5.30 & 6.08 & 6.81 & 1.92 & 16.56 & 2.99 & \multirow{2}{*}{$-6.57 * * *$} \\
\hline & 1 & 5,200 & 11.87 & 12.65 & 14.82 & 1.98 & 17.81 & 3.58 & \\
\hline \multicolumn{10}{|l|}{ Student characteristics } \\
\hline \multirow{2}{*}{ Woman in the program (\%) } & 0 & 811 & 27.78 & 49.95 & 71.42 & .00 & 100.00 & 26.30 & \multirow{2}{*}{.91} \\
\hline & 1 & 5,197 & 25.00 & 49.04 & 74.57 & .00 & 100.00 & 28.87 & \\
\hline \multirow{2}{*}{ First-year students (\%) } & 0 & 811 & 24.47 & 33.23 & 41.18 & .00 & 86.67 & 13.44 & \multirow{2}{*}{$1.82^{* * *}$} \\
\hline & 1 & 5,197 & 22.39 & 31.41 & 39.13 & .00 & 100.00 & 13.03 & \\
\hline \multirow{2}{*}{ Second-year students (\%) } & 0 & 811 & 18.75 & 24.41 & 28.57 & .00 & 61.90 & 9.25 & \multirow{2}{*}{$-.75 * *$} \\
\hline & 1 & 5,197 & 19.25 & 25.16 & 30.56 & .00 & 64.71 & 9.09 & \\
\hline \multirow{2}{*}{ Third-year students (\%) } & 0 & 811 & 13.79 & 20.23 & 25.81 & .00 & 61.54 & 9.39 & \multirow{2}{*}{-.16} \\
\hline & 1 & 5,197 & 14.29 & 20.39 & 26.00 & .00 & 62.22 & 8.99 & \\
\hline \multirow{2}{*}{ Fourth-year students (\%) } & 0 & 811 & 6.25 & 11.79 & 16.67 & .00 & 57.14 & 7.67 & \multirow{2}{*}{$-4.96 * * *$} \\
\hline & 1 & 5,197 & 9.76 & 16.75 & 23.08 & .00 & 61.54 & 9.60 & \\
\hline \multirow{2}{*}{ Fifth-year students (\%) } & 0 & 811 & .00 & 5.40 & 8.22 & .00 & 30.00 & 5.89 & \multirow{2}{*}{$1.67^{* * *}$} \\
\hline & 1 & 5,197 & .00 & 3.72 & 5.88 & .00 & 46.15 & 4.44 & \\
\hline \multirow{2}{*}{ Seniors (\%) } & 0 & 811 & .00 & 4.11 & 5.312 & .00 & 61.82 & 4.11 & \multirow{2}{*}{$1.97^{* * *}$} \\
\hline & 1 & 5,197 & .00 & 2.14 & 3.12 & .00 & 33.33 & 2.14 & \\
\hline \multirow{2}{*}{ Study time } & 0 & 787 & 25.88 & 29.36 & 33.46 & 11.27 & 44.60 & 6.21 & \multirow{2}{*}{$3.13 * * *$} \\
\hline & 1 & 5,161 & 20.19 & 26.23 & 31.55 & 10.50 & 50.14 & 7.28 & \\
\hline
\end{tabular}

Where ${ }^{* * *}$ denotes significant at $0.01 \%$-level. ${ }^{* *} p<0.05 ;{ }^{*} p<0.1$

${ }^{\delta} 0$ : No AD policy implemented (the control group). 1 : AD policy has been eventually implemented (the treatment group) 
Table 4: Descriptive statistics of the outcome variables, and equality of means between control and treatment group

\begin{tabular}{|c|c|c|c|c|c|c|c|c|c|}
\hline Variable & $\begin{array}{l}\text { Control/treat- } \\
\text { ment group }\end{array}$ & N & First quartile & Mean & Third quartile & Min & Max & SD & $\begin{array}{c}\text { T-test }(\mathrm{dif}= \\
\text { mean(0)-mean(1) }\end{array}$ \\
\hline \multirow{2}{*}{ Student dropout } & 0 & 607 & 10.50 & 17.25 & 23.20 & 0 & 100.00 & 11.16 & \multirow{2}{*}{$-8.83 * * *$} \\
\hline & 1 & 2,954 & 18.50 & 26.08 & 32.10 & 0 & 100.00 & 12.27 & \\
\hline \multirow{2}{*}{ Student graduation } & 0 & 593 & 40.90 & 52.48 & 64.60 & 0 & 100.00 & 17.79 & \multirow{2}{*}{$-10.61 * * *$} \\
\hline & 1 & 2,418 & 52.30 & 63.09 & 75.70 & 0 & 100.00 & 18.33 & \\
\hline \multirow{2}{*}{$\begin{array}{l}\text { Overall Satisfaction with } \\
\text { the program }\end{array}$} & 0 & 560 & 7.30 & 7.52 & 7.75 & 6.37 & 8.57 & .34 & \multirow{2}{*}{$.48^{* * *}$} \\
\hline & 1 & 2,909 & 6.69 & 7.04 & 7.37 & 5.00 & 9.00 & .48 & \\
\hline \multirow{2}{*}{$\begin{array}{l}\text { Average NSE score (own } \\
\text { constructed variable from } \\
\text { the means of all } \\
\text { questionnaire items) }\end{array}$} & 0 & 812 & 6.91 & 7.07 & 7.24 & 6.19 & 7.97 & .26 & \multirow{2}{*}{$.31 * * *$} \\
\hline & 1 & 5,200 & 6.54 & 6.76 & 6.96 & 5.43 & 8.11 & .32 & \\
\hline \multirow{2}{*}{ Feasibility of the program } & 0 & 367 & 6.23 & 6.51 & 6.96 & 3.87 & 8.05 & .72 & \multirow{2}{*}{$-.43 * * *$} \\
\hline & 1 & 2,062 & 6.67 & 6.94 & 7.28 & 3.40 & 8.67 & .53 & \\
\hline
\end{tabular}

Where $* * *$ denotes significant at $0.01 \%$-level. $* * \mathrm{p}<0.5 ; * \mathrm{p}<0.1$

${ }^{\delta} 0$ : No AD policy implemented (the control group). 1: AD policy has been eventually implemented (the treatment group) 


\section{Results}

\subsection{Trend analysis}

Before presenting the estimation results, we obtain some intuitive information on the data by a trend analysis. In particular, we plot the relationship between the AD policy and the outcome variables at different points in time before and after the implementation. To do so, we create a variable equal to 0 for the year in which the AD policy is introduced in the academic program. The years after the introduction receive a positive number, while the years before the introduction correspond to a negative number.

We observe that student dropout and student graduation both increased around the introduction of an AD policy (Appendix B, Figure 1-2). The trend is in line with Bénabou and Tirole (2003) who predict that setting a performance standard results in motivating some students to improve their performance while discouraging others to making an attempt at all. Consequently this latter group will drop out.

The trend analysis for overall satisfaction with the program (Appendix B, Figure 3) suggests a decline of overall student satisfaction in the year the AD policy is first employed. This trend is confirmed for the average NSE score, which indicates a steep decline the year the AD policy is introduced (Appendix B, Figure 4). The above trend is in line with labor market studies that report that organizational stress and job satisfaction are inversely related (e.g., Hollon \& Chesser, 1976; Miles, 1976). In a similar vein, Cotton et al. (2002) link characteristics of student work environment, such as high work pressure, low control and low support, to psychological stress. The work design influences satisfaction in a similar way, meaning that high demands and low control results in low satisfaction (Cotton et al. 2002). The implementation of an AD policy can have a similar effect on the work design of students, causing more pressure to perform well during their first year of enrolment. In turn this pressure can result in higher levels of stress and lower levels of satisfaction.

Figure 5 (Appendix B) represents the relationship between students' opinions regarding the feasibility of the program before and after the implementation. Concerning feasibility of the program, the trend of the student opinions can go two-way. First, first-year students may find the program less feasible as they have to achieve a minimum number of credits, resulting in lower opinions. Second, students who passed the credit threshold, may find the program more feasible and rate the likelihood of completing the program higher. Looking at the figure, we observe that students find the program more feasible in the year the AD policy is first introduced. Further, we observe a steep decline in satisfaction with program feasibility one year before the introduction of an AD policy. This decrease can be due to an announcement effect.

It should be noted that Figure 1 and 2 provide evidence for the rather 'exogenous' introduction of an $\mathrm{AD}$ policy. As we do not observe that academic degrees introduce an $\mathrm{AD}$ policy because of increasing dropout rates or declining graduation rates, it makes us more confident on the exogeneity assumption.

While the above analyses describe the trends of the outcome variables in relation to different points before and after the introduction of an AD policy, one drawback of this method is that we do not have a control group. The use of a control group is needed in order to eliminate temporary trends in the outcome variable or effects of events, other than the treatment, that occurred between the measuring periods. To overcome this problem, we will apply the suggested difference-in-differences type of estimator. 


\subsection{Difference-in-Differences type of estimator}

The estimation results for Equation (3) are presented in Table 5. The results indicate that the introduction of an $\mathrm{AD}$ policy (captured by the variable of interest $A D$ policy) is significantly correlated to all outcome variables. The results suggest that the introduction of an AD policy leads to a significant increase of student dropout and student graduation ${ }^{10}$. Moreover, due to the introduction of an $\mathrm{AD}$ policy, student dropout will increase by $7.5 \%$ while student graduation will increase by $3.3 \%$. The results further show that the introduction of an AD policy leads to a significant decrease of overall satisfaction (i.e. .48 point on a ten point scale) and average NSE score (i.e. .36 point on a ten point scale). Perceived program feasibility increases significantly due to the implementation of an AD policy (i.e. .43 point on a ten point scale).

The group specific effects explain also a part of the variation in student performance and student satisfaction. The results show that programs that eventually will implement an AD policy have a higher level of student dropout and student graduation in comparison with programs that will never employ an AD policy. Next, programs that will apply an AD policy (i.e., $\mathrm{D}=1$ ) receive a higher average NSE score compared to programs that will never apply an AD policy at some point in time.

Looking at the time-specific effects, we observe mixed results. First, the results for student dropout show no time-specific results. For student graduation we only detect a decline in the academic year 2007-08 in comparison to the reference year. Furthermore, it seems that overall student satisfaction and satisfaction with program feasibility decreases in time. However, while the average NSE score in the years 2005-06 and 2008-09 is higher than in 2003-04, it is lower in the years 200607 and 2007-08 compared to 2003-04.

We additionally run a second model specification which includes various covariates (see table 6). We also cluster the standard errors at the level of the academic field of the program (i.e. field of study), such as economics, medicine or law. Finally, we add the variable student enrollment, which was indicated in section 4.2 to correlate with the introduction of an AD policy. The results are in line with our previous outcomes. In particular, we observe that an AD policy has a significant positive influence on student dropout, student graduation and satisfaction with program feasibility. Specifically, student dropout, student graduation and satisfaction with program feasibility rise by $5.8 \%, 7 \%$ and .33 point (on a ten point scale) respectively. The implementation of an AD policy has again a significant negative influence on overall student satisfaction (i.e. .35 point on a ten point scale) and average NSE score (i.e. .26 point on a ten point scale).

Significantly more students in programs that eventually will implement an AD policy drop out and graduate on time in comparison to students in programs that will never introduce an AD policy. Students in programs that eventually will introduce an AD policy have a significantly higher overall satisfaction and NSE scores compared to students in programs that will never employ an AD policy.

It is observed that student graduation is declining in later years. The results indicate that programs receive significantly lower scores for overall satisfaction and satisfaction with program feasibility in later years. The average NSE scores decline in the academic years 2005-06 and 2008-09 in comparison to the academic year 2003-04. These results are consistent with a study of Steenkamp et al. (2008b) that satisfaction of students, measured by the NSE, decreased slightly from 1996 until 2005.

\footnotetext{
${ }^{10}$ A factor analysis points out that student dropout and student graduation are no substitutes (uniqueness of the estimates is .9455) and thus should be included separately in the analyses.
} 
We find with respect to the covariates that programs with a high percentage of female students have a lower dropout rate and receive higher satisfaction compared to programs with a low percentage of female students. This is in line with findings by Bruinsma (2004), Andrews et al. (2012), and Umbach and Porter (2002). Further, we observe that programs with a higher percentage of students who are enrolled for two, three or four years have a significantly higher graduation rate than programs with a higher percentage of first-year students. Programs with a high percentage of students enrolled for the fifth year have a significant lower graduation rate than programs with a high percentage of first-year students. This finding is not surprising since students enrolled for the fifth time (in the same program) will not graduate within the nominal study time, while students enrolled for the second, third or fourth time can still graduate on time. The results also show that programs with a high percentage of students who are enrolled for four years have significantly lower scores on overall satisfaction than programs with a high percentage of first-year students. We find similar results for the average NSE score. More specifically, students enrolled for two or four years have a significantly lower average NSE score compared to first-year students. Interestingly, we find that students enrolled for more than five years have a significantly higher NSE score. Concerning the feasibility of the program, programs with a high percentage of students who are three or four years enrolled score significantly higher on the feasibility of the program compared to programs with a high percentage of first-year students. This result was expected as most students enrolled for the third or fourth year passed the credit-threshold, resulting in a higher likelihood of graduating compared to first-year student. However, programs with a high percentage of students who are five years or longer enrolled show significantly lower satisfaction with program feasibility compared to programs with a high percentage of first-year students. These students may fear that they will not pass, resulting in a lower satisfaction with the feasibility of the program compared to students enrolled for the first time. Next, as expected, we find a significant negative relationship between study time and student dropout and a significant positive relationship between study time and student graduation. We also observe that programs receive higher overall satisfaction and average NSE score when students study more. Surprisingly, satisfaction regarding feasibility of the program is negatively correlated with study time. As we do not know the direction of the correlation, reverse causality might be an issue here. Finally, we observe that the variable student enrollment has a small significant influence on all outcome variables.

Various alternative specifications deliver similar outcomes, but are not reported here to save some space (available upon request). Additional control variables include the average number of credits achieved by the students in the program and the type of admission criteria to enter the program. Similar results are found when the variables number of years enrolled and study time are excluded from the analysis. By clustering at the institutional level, at location level and at program level, we find robust outcomes concerning the direction of the relationships. The significance of the results sometimes decreases, but this is not surprising since the analyses are done in smaller groups of observations. 
Table 5: Regression outcomes of Equation (3)

\begin{tabular}{|c|c|c|c|c|c|c|c|c|c|c|}
\hline & \multicolumn{2}{|c|}{ Student dropout } & \multicolumn{2}{|c|}{ Student graduation } & \multicolumn{2}{|c|}{ Overall satisfaction } & \multicolumn{2}{|c|}{ Average NSE score } & \multicolumn{2}{|c|}{$\begin{array}{l}\text { Satisfaction with } \\
\text { program feasibility }\end{array}$} \\
\hline & Coef. & SE & Coef. & SE & Coef. & SE & Coef. & SE & Coef. & SE \\
\hline Intercept & $17.028 * * *$ & 1.636 & $54.346 * * *$ & 2.527 & $7.804 * * *$ & .031 & $7.072 * * *$ & 0.183 & $6.647 * * *$ & .045 \\
\hline$D(0=$ never an $A D$ policy $)$ & $1.934 * *$ & .908 & $6.856^{* * *}$ & 1.399 & 0.050 & .033 & $.046 * *$ & .021 & .059 & .058 \\
\hline \multicolumn{11}{|l|}{ Year ( 2003-04= ref. year) } \\
\hline $2004-05$ & -2.169 & 1.730 & 0.977 & 2.672 & -0.061 & .038 & -.016 & .012 & -0.038 & .054 \\
\hline 2005-06 & -0.083 & 1.688 & -3.420 & 2.608 & $-.183^{* * *}$ & .034 & $.051 * * *$ & .012 & $-.280 * * *$ & .056 \\
\hline 2006-07 & 1.567 & 1.687 & -3.381 & 2.605 & $-.412 * * *$ & .036 & $-.090 * * *$ & .021 & $-.212 * * *$ & .055 \\
\hline 2007-08 & 1.061 & 1.700 & $-4.604^{*}$ & 2.626 & $-.351 * * *$ & .037 & $-.104 * * *$ & .021 & $-.216 * * *$ & .053 \\
\hline 2008-09 & -0.240 & 1.708 & 2.878 & 2.774 & & & $.118^{* * *}$ & 0.025 & $-.158 * * *$ & .057 \\
\hline $\begin{array}{l}\text { AD policy } \\
\text { ( } 0=\text { before the } \\
\text { implementation of an } A D \\
\text { policy) }\end{array}$ & $7.469 * * *$ & .820 & $3.271^{* * *}$ & 1.196 & $-.481 * * *$ & .030 & $-.357 * * *$ & .019 & $.425^{* * *}$ & .056 \\
\hline $\mathrm{N}$ & \multicolumn{2}{|c|}{3,561} & \multicolumn{2}{|c|}{3,011} & \multicolumn{2}{|c|}{3,092} & \multicolumn{2}{|c|}{5,600} & \multicolumn{2}{|c|}{2,429} \\
\hline $\mathrm{R}^{2}$ & \multicolumn{2}{|c|}{.102} & \multicolumn{2}{|c|}{.071} & \multicolumn{2}{|c|}{.291} & \multicolumn{2}{|c|}{.206} & \multicolumn{2}{|c|}{.108} \\
\hline Adjusted $\mathrm{R}^{2}$ & \multicolumn{2}{|c|}{.100} & \multicolumn{2}{|c|}{.069} & \multicolumn{2}{|c|}{.289} & \multicolumn{2}{|c|}{.205} & \multicolumn{2}{|c|}{.105} \\
\hline
\end{tabular}

Where $* * *, * *$, and $*$ denote, respectively, significance at 1,5 and $10 \%$-level. The sample size varies due to missing values in the covariates. 
Table 6: Regression outcomes for the DiD type of estimation with covariates for the outcome variables

\begin{tabular}{|c|c|c|c|c|c|c|c|c|c|c|}
\hline & \multicolumn{2}{|c|}{ Student dropout } & \multicolumn{2}{|c|}{ Student graduation } & \multicolumn{2}{|c|}{ Overall satisfaction } & \multicolumn{2}{|c|}{ Average NSE score } & \multicolumn{2}{|c|}{$\begin{array}{l}\text { Satisfaction with } \\
\text { program feasibility }\end{array}$} \\
\hline & Coef. & SE & Coef. & SE & Coef. & SE & Coef. & SE & Coef. & SE \\
\hline Intercept & $20.851 * * *$ & 2.610 & $34.799 * * *$ & 3.985 & $7.487^{* * *}$ & .074 & $7.069 * * *$ & .040 & $7.547 * * *$ & .111 \\
\hline $\begin{array}{l}\text { D } \\
\text { ( } 0=\text { never an } A D \text { policy) }\end{array}$ & $1.772 * *$ & .823 & $6.426 * * *$ & 1.279 & $.065^{* *}$ & .030 & $.056^{* * *}$ & .019 & -.057 & .052 \\
\hline \multicolumn{11}{|l|}{ Year } \\
\hline \multicolumn{11}{|l|}{ (2003-04= reference year) } \\
\hline $2004-05$ & -.621 & 1.695 & -1.417 & 2.461 & $-.153 * * *$ & .039 & -.013 & .020 & $-.129 * * *$ & .052 \\
\hline 2005-06 & .807 & 1.658 & -3.917 & 2.408 & $-.209 * * *$ & .035 & $.045^{* *}$ & .020 & $-.307^{* * *}$ & .056 \\
\hline 2006-07 & 2.362 & 1.673 & $-4.708 *$ & 2.430 & $-.399 * * *$ & .035 & $-.068 * * *$ & .021 & $-.296 * * *$ & .051 \\
\hline 2007-08 & 2.037 & 1.679 & $-6.465 * * *$ & 2.440 & $-.250 * * *$ & .038 & -.021 & .021 & $-.352 * * *$ & .051 \\
\hline 2008-09 & .575 & 1.678 & .160 & 2.558 & & & $.093^{* * *}$ & .024 & $-.387 * * *$ & .053 \\
\hline $\begin{array}{l}\text { AD policy } \\
\text { ( } 0=\text { before the implementation of an AD policy) }\end{array}$ & $5.793 * * *$ & .823 & $6.980 * * *$ & 1.193 & $-.345^{* * *}$ & .029 & $-.264 * * *$ & .018 & $.329 * * *$ & .050 \\
\hline $\begin{array}{l}\text { Gender } \\
\text { ( } 0=\text { men) }\end{array}$ & $-.022^{* *}$ & .010 & .162 & .017 & $.001 * * *$ & .000 & $.001 * * *$ & .000 & $.002 * * *$ & .001 \\
\hline \multicolumn{11}{|l|}{$\begin{array}{l}\text { Number of years in the program } \\
\text { ( reference category= } 1 \text { year) }\end{array}$} \\
\hline 2 years & -032 & .205 & $.127^{* * *}$ & .042 & -.001 & .001 & $-.002 * * *$ & .000 & 0.001 & .001 \\
\hline 3 years & -.001 & .024 & $.232 * * *$ & .038 & -.001 & .001 & -.001 & .000 & $.003 * * *$ & .001 \\
\hline 4 years & -.028 & .025 & $.127^{* * *}$ & .041 & $-.004 * * *$ & .000 & $-.004 * * *$ & .000 & $.006^{* * *}$ & .001 \\
\hline 5 years & -.053 & 0.049 & $-.316^{* * *}$ & .077 & .001 & .001 & -.001 & .001 & $-.028 * * *$ & .003 \\
\hline$>5$ years & -.035 & .058 & -.014 & .089 & .001 & .002 & $.003^{* *}$ & .001 & $-.028 * * *$ & .003 \\
\hline Study time & $-.318 * * *$ & .049 & $.197 * *$ & .077 & $.012^{* * *}$ & .001 & $.006 * * *$ & .001 & $-.027 * * *$ & .002 \\
\hline Number of students & $.0001 * * *$ & .000 & $-.0001 * * *$ & .000 & -.00001 & .000 & -.000 & .000 & $.000 * * *$ & .000 \\
\hline Field of study & \multicolumn{2}{|c|}{ YES } & \multicolumn{2}{|c|}{ YES } & \multicolumn{2}{|c|}{ YES } & \multicolumn{2}{|c|}{ YES } & \multicolumn{2}{|c|}{ YES } \\
\hline $\mathrm{N}$ & \multicolumn{2}{|c|}{3,539} & \multicolumn{2}{|c|}{2,997} & \multicolumn{2}{|c|}{3,032} & \multicolumn{2}{|c|}{5,489} & \multicolumn{2}{|c|}{2,409} \\
\hline $\mathrm{R}^{2}$ & \multicolumn{2}{|c|}{.096} & \multicolumn{2}{|c|}{.159} & \multicolumn{2}{|c|}{.316} & \multicolumn{2}{|c|}{.267} & \multicolumn{2}{|c|}{.237} \\
\hline
\end{tabular}

Where ***,**, and * denote, respectively, significance at 1, 5 and 10\%-level. The sample size varies due to missing values in the covariates. 


\section{Robustness tests}

\subsection{Propensity score matching}

As a first robustness test we use propensity score matching (PSM). PSM is a statistical analysis that allows us to match treated units to non-treated units who have similar characteristics, hereby reducing the bias arising from working with an inappropriate control group (Dehejia \& Wahba, 2002; Peikes et al., 2008; Rosenbaum \& Rubin, 1983). In particular, the possibility of bias arises when we estimate a treatment effect on groups with different characteristics. This increases the risk that the difference in outcome depends on the difference in characteristics, rather than it is caused by the treatment. Observational studies often have a problem of biasedness, because the assignment of treatment to research subjects is not randomized, resulting in a control and treatment group that are not balanced regarding covariates. Matching attempts to mimic randomization by creating a treatment group that is comparable on all observable characteristics to the control group.

We match on the covariates at the institutional-level and student-level described in table 1. The former group of covariates consists of the student-staff ratio, and the number of students enrolled, while the latter group consists of gender, number of years enrolled, study time (as a proxy for the requirements of the program), and year of the questionnaire (given that students are more critical in later years than earlier years). Further, we include the variable vocational-university that indicates if the program is at university level or at vocational higher institute level and the variable field of study. To assess the validity of the comparison groups, we compare treatment-control group differences in outcomes (based on the quasi-experimental design) with treatment-comparison differences (based on the non-experimental PSM design).

Table 7 shows that, for the treated units, student dropout and satisfaction regarding feasibility of the program decreases when based on the matched sample. However, student graduation, overall satisfaction and average NSE score are underestimated when based on the unmatched sample. Subsequently, with the exception of student graduation, the estimated effects by the PSM method are smaller than under the earlier estimations.

More precisely, for student dropout, we find by the PSM a significant positive influence (tstat $=19.00)$, but compared to the regression specifications the effect loses some of its strength ( $t$-stat $=8.79)$. Based on the unmatched sample, we find a significant positive impact $(\mathrm{t}$-stat $=12.44)$ for student graduation. Regarding the average student satisfaction and the overall NSE score, we find a negative significant influence based on the unmatched sample (respectively, t-stat $=-28.40$ and $t$-stat $=-32.66$ ), compared to a smaller significant negative influence based on the matched sample (respectively, $\mathrm{t}$-stat $=-12.90$ and $\mathrm{t}$-stat $=-11.74)$. For satisfaction with program feasibility both methods estimated impacts to be positive and significant (respectively, t-stat $=14.89$ and $\mathrm{t}$-stat $=$ 7.94). Note, that adding extra covariates, such as the average number of ECTS achieved by the students in the program and the type off admission criteria, deliver similar results. 
Table 7: Robustness check of the five outcome variables using propensity score matching

\begin{tabular}{lcccccc}
\hline Variable & Sample & Treated & Controls & Difference & SE & t-stat \\
\hline \multirow{2}{*}{ Student dropout } & Unmatched & 26.731 & 17.788 & 8.943 & .471 & 19.00 \\
& Matched & 22.343 & 17.788 & 4.555 & .518 & 8.79 \\
\hline \multirow{2}{*}{ Student graduation } & Unmatched & 63.642 & 54.394 & 9.248 & .743 & 12.44 \\
& Matched & 67.450 & 54.394 & 13.056 & .879 & 14.85 \\
\hline \multirow{2}{*}{ Overall satisfaction } & Unmatched & 7.007 & 7.530 & -.523 & .018 & -28.40 \\
& Matched & 7.284 & 7.530 & -.246 & .019 & -12.90 \\
\hline \multirow{2}{*}{ Average NSE score } & Unmatched & 6.733 & 7.080 & -.347 & .009 & -32.66 \\
& Matched & 6.935 & 7.080 & -.145 & .011 & -11.74 \\
\hline \multirow{2}{*}{ Satisfaction with program } & Unmatched & 6.960 & 6.541 & .419 & .028 & 14.89 \\
feasibility & Matched & 6.886 & 6.541 & .435 & .043 & 7.94 \\
\hline
\end{tabular}

\subsection{Different subsamples}

As a second robustness test we estimate Equation (3) for different subsamples. The first subsample consists of observations from the years 2003-04 and 2004-05. Between those years, the common trend assumption was not met (see appendix A, Table 1-3). The results, presented in Table 8, are identical to those obtained by the full sample, which yields confidence in the earlier results.

Second, as the common trend assumption was not met for the years 2005-06 and 2006-07 (see appendix A; Table 1-3), we only include observations from those years in the second subsample. The results, presented in Table 9, indicate the robustness of the outcomes.

Third, we include only observations from higher education institutes in urban areas. This distinction is made as students from urban and rural areas can differ in background, ethnicity, grade point average, socio-economic situation (SES), enrollment curriculum and educational level of parents (McCracken and Barcinas, 1991), which in turn may influence the findings. Again, we confirm our previous findings (see Table 10).

We conclude that the estimation outcomes are robust for the different subsamples. 
Table 8: Regression outcomes for Equation (3) using observations from the years 2003-04 and 200405

\begin{tabular}{|c|c|c|c|c|c|}
\hline & Student dropout & Student graduation & Overall satisfaction & Average NSE score & $\begin{array}{l}\text { Satisfaction with } \\
\text { program feasibility }\end{array}$ \\
\hline \multicolumn{6}{|c|}{ Model 1 (without covariates) } \\
\hline & Coef. & Coef. & Coef. & Coef. & Coef. \\
\hline \multirow[t]{2}{*}{ treatment effect } & $5.968 * * *$ & $8.945^{* * *}$ & $-.362 * * *$ & $-.295 * * *$ & $.297 * * *$ \\
\hline & [1.443] & [2.259] & {$[.068]$} & {$[.024]$} & {$[.074]$} \\
\hline $\mathrm{N}$ & 471 & 460 & 640 & 1,921 & 670 \\
\hline$R^{2}$ & .091 & .178 & .192 & .195 & .151 \\
\hline adjusted $\mathrm{R}^{2}$ & .086 & .173 & .188 & .193 & .148 \\
\hline \multicolumn{6}{|c|}{ Model2 (with covariates) } \\
\hline & Coef. & Coef. & Coef. & Coef. & Coef. \\
\hline \multirow[t]{2}{*}{ treatment effect } & $6.288 * * *$ & $10.717^{* * *}$ & $-.344 * * *$ & $-.275 * * *$ & $.274^{* * *}$ \\
\hline & [1.599] & [2.420] & [.068] & {$[.024]$} & {$[.068]$} \\
\hline $\mathrm{N}$ & 468 & 458 & 610 & 1,853 & 666 \\
\hline$R^{2}$ & .115 & .225 & .207 & .267 & .259 \\
\hline
\end{tabular}

Where $* * *, * *$, and $*$ denote, respectively, significance at 1,5 and 10\%-level, standard errors between brackets. The sample size varies due to missing values in the covariates.

Table 9: Regression outcomes for Equation (3) using observations from the years 2005-06 and 200607

\begin{tabular}{|c|c|c|c|c|c|}
\hline & Student dropout & Student graduation & Overall satisfaction & Average NSE score & $\begin{array}{l}\text { Satisfaction with } \\
\text { program feasibility }\end{array}$ \\
\hline \multicolumn{6}{|c|}{ Model 1 (without covariates) } \\
\hline & Coef. & Coef. & Coef. & Coef. & Coef. \\
\hline \multirow[t]{2}{*}{ treatment effect } & $7.711^{* * *}$ & $3.217^{*}$ & $-.513 * * *$ & $-.397 * * *$ & $.886^{* * *}$ \\
\hline & [1.157] & {$[1.750]$} & [.041] & {$[.028]$} & [.104] \\
\hline $\mathrm{N}$ & 1,594 & 1,577 & 1,920 & 2,345 & 801 \\
\hline $\mathrm{R}^{2}$ & .088 & .044 & .258 & .209 & .136 \\
\hline adjusted $\mathrm{R}^{2}$ & .086 & .043 & .257 & .208 & .133 \\
\hline \multicolumn{6}{|c|}{ Model2 (with covariates) } \\
\hline & Coef. & Coef. & Coef. & Coef. & Coef. \\
\hline \multirow[t]{2}{*}{ treatment effect } & $5.833 * * *$ & $6.794 * * *$ & $-.307 * * *$ & $-.239 * * *$ & $.644^{* * *}$ \\
\hline & [1.188] & {$[1.712]$} & {$[.035]$} & [.027] & [.099] \\
\hline $\mathrm{N}$ & 1,586 & 1,569 & 1,892 & 2,311 & 789 \\
\hline $\mathrm{R}^{2}$ & .080 & .124 & .252 & .232 & .270 \\
\hline
\end{tabular}

Where $* * *, * *$, and $*$ denote, respectively, significance at 1,5 and 10\%-level, standard errors between brackets. The sample size varies due to missing values in the covariates. 
Table 10: Regression outcomes for Equation (3) using observations from higher educational institutes in urban areas

\begin{tabular}{|c|c|c|c|c|c|}
\hline & Student dropout & Student graduation & Overall satisfaction & Average NSE score & $\begin{array}{c}\text { Satisfaction with } \\
\text { program feasibility }\end{array}$ \\
\hline \multicolumn{6}{|c|}{ Model 1 (without covariates) } \\
\hline & Coef. & Coef. & Coef. & Coef. & Coef. \\
\hline \multirow[t]{2}{*}{ treatment effect } & $7.354 * * *$ & $3.234^{* *}$ & $-.484 * * *$ & $-.352 * * *$ & $.338 * * *$ \\
\hline & {$[.946]$} & [1.452] & [.033] & {$[.020]$} & {$[.061]$} \\
\hline $\mathrm{N}$ & 2,113 & 1,814 & 1,910 & 3,406 & 1,417 \\
\hline $\mathrm{R}^{2}$ & .010 & .059 & .355 & .242 & .102 \\
\hline adjusted $R^{2}$ & .097 & .055 & .352 & .240 & .098 \\
\hline \multicolumn{6}{|c|}{ Model2 (with covariates) } \\
\hline & Coef. & Coef. & Coef. & Coef. & Coef. \\
\hline \multirow[t]{2}{*}{ treatment effect } & $4.754 * * *$ & $6.170 * * *$ & $-.329 * * *$ & $-.243 * * *$ & $.290 * * *$ \\
\hline & {$[.946]$} & [1.384] & [.031] & [.019] & {$[.056]$} \\
\hline $\mathrm{N}$ & 2,109 & 1,810 & 1,881 & 3,357 & 1,415 \\
\hline$R^{2}$ & .101 & .143 & .341 & .236 & .244 \\
\hline
\end{tabular}

Where $* * *, * *$, and $*$ denote, respectively, significance at 1,5 and 10\%-level, standard errors between brackets. The sample size varies due to missing values in the covariates.

\section{Conclusions, further research and policy implications}

The growing accountability of higher education institutes makes them increasingly selective in accepting students. Students in programs with academic dismissal (AD) policies can be removed from the institution when they do not make satisfactory study progress. It is thus a form of selection after the gate. The credit-threshold students must pass differs by institution and by academic degree. Although the effect of such an AD policy on performance is measured by a few studies (e.g. De Koning et al., 2014; Gijbels et al., 2004), little is known about the effect of this type of selection tool on student satisfaction. This paper is the first to examine empirically the effect of the introduction of an AD policy on both student performance and student satisfaction. Using Dutch nationwide data, the effect of the introduction of a student selection tool on student graduation, student dropout and student satisfaction is investigated.

Our results suggest that, on average, student dropout and student graduation increased due to the introduction of an AD policy. Next, we found that the introduction of an AD policy leads to a decrease of student satisfaction. The outcomes also indicate that student satisfaction regarding program feasibility increases because of the implementation of an AD policy. Looking at the period specific effects, we observe that student graduation rates are lower in more recent years. This is an alarming finding since higher educational institutes are increasingly aware of the benefits of graduation 'on time'. The results also indicate that student satisfaction used to be higher in the past. This result can be explained by the relationship between satisfaction and expectations. As students increasingly perceive themselves to be customers, due to the tuition fees and growth of consumerism in public services, their expectations rise (Tricker, 2005). In this context, expectations of students are high and include, for example, flexibility and choice in the delivery of education, and a two way communication process between themselves and the university (Davies, 2002). Due to this increase in expectations it is possible that the actual performance of the higher educational institutes is below the expectations of the students, resulting in dissatisfaction (Appleton-Knapp \& Krentler, 2006; Bitner \& Hubbert, 1994). Important to note is that the observed results are very robust. 
This paper yields some insightful policy advice. An AD policy enables effective selection of students after the first year. While, for equity arguments, selection at the gate is often undesired, this paper indicates that selection after the gate might be effective. Nevertheless, the negative influence on student satisfaction suggests that the introduction of an admission policy should be complemented by measures to improve, or at least stabilize, student satisfaction.

We observed that the AD policy is an effective selection tool. However, the level of the AD policy norm is also important. A very high AD policy threshold will probably not only result into a steep increase of graduation rates but also in a considerate increase in dropout rate. This can lead to the dismissal of many students who would have graduated on time. A too low AD policy norm, on the other hand, can result in too few dismissed students. Moreover, the optimal AD threshold is not easy to determine and depends on the type of academic program and the current dropout rate. A study program in the medical field, for example, will require more from students than a program in the social field, and will thus need a higher AD policy threshold to be an effective selection tool. Study programs with a current high dropout rate may not want to introduce an even higher norm because this can result in few students who are able to enroll in the second year. Programs with a low dropout rate can opt to start with a low credit norm during the first years after introduction and increase it if the selection does not seem sufficient. Important to note is that there is no 'one-size-fits-all' AD policy norm.

This paper provides several lines for future research. First, the current study does not focus on the underlying mechanisms between an AD policy, student performance and student satisfaction, as we do not measure intervening process variables. Additional research is necessary to exploit the mechanisms between an AD policy and its outcome variables. Second, we investigated the effect of the introduction of an $\mathrm{AD}$ policy on performance and satisfaction using program-level data. As such we could not distinguish students in their first year and students in later years. Those two groups of students will respond different on an AD policy. Indeed, first-year students still need to face the AD policy while students in later years do not. We expect that the former group will be more affected by an $\mathrm{AD}$ policy in terms of performance. By using data on student-level, the effect of the introduction of an AD policy on performance and satisfaction of first-year students can be exploited. Third, because we could not distinguish students that received a negative obligatory advice, the treat of a selection problem exist. Future research can focus solely on this type of students and investigate the effect of receiving a negative advice on student satisfaction and on the academic career. Future research could also focus on whether students that received a negative obligatory advice and started a new study are more or less satisfied than students who never received a negative obligatory advice. This can have a large impact on the policy decisions of institutions. Fourth, it is also possible that students choose a study program based on the presence of an $\mathrm{AD}$ policy. If this is the case, more motivated and talented students will attend study programs with an AD policy. Future research can focus on investigating this matter. Finally, the study used a sample of Dutch higher education programs, and the extent to which the results are generalized to other countries is not known. Further research can generalize our results to other countries. 


\section{References}

Abadie, A. (2005). Semiparametric difference-in-differences estimators. The Review of Economic Studies, 72(1), 1-19.

Adelman, C. (1991). Women at Thirty something: Paradoxes of Attainment. Washington, DC: Office of Educational Research and Improvement.

Adelman, C. (2006). The Toolbox Revisited: Paths to Degree Completion From High School Through College. Washington, DC: US Department of Education.

Albouy, D. (2004). Program evaluation and the difference in difference estimator. Retrieved 07/02, 2013, from http://emlab.berkeley.edu/users/webfac/saez/e131_s04/diff.pdf

Alexander, F. K. (2000). The changing face of accountability: Monitoring and assessing institutional performance in higher education. Journal of Higher Education, 71(4), 411-431.

Andrews, J., Higson, H., Green, P. \& Jones, C. (2012). How do you encourage student engagement in placement in placement learning? Conference proceedings 2012, 050.

Appleton-Knapp, S. L., \& Krentler, K. A. (2006). Measuring student expectations and their effects on satisfaction: The importance of managing student expectations. Journal of marketing education, 28(3), 254-264.

Arnold, I. J. (2014). The effectiveness of academic dismissal policies in Dutch university education: an empirical investigation. Studies in Higher Education, (ahead-of-print), 1-17.

Arnold, I., \& Van den Brink, W. (2010). Naar een effectiever bindend studieadvies [ Towards a more effective binding study advice]. Tijdschrift voor Hoger Onderwijs en Management, 5(10), 10-13.

Astin, A. W., \& Solmon, L. C. (1981). Are reputational ratings needed to measure quality? Change: The Magazine of Higher Learning, 13(7), 14-19.

Bailey, T., Calcagno, J. C., Jenkins, D., Leinbach, T., \& Kienzl, G. (2006). Is student-right-to-know all you should know? An analysis of community college graduation rates. Research in Higher Education, 47(5), 491-519

Bean, J. P. (1990). Why students leave: Insights from research. In D. Hossler (Ed.), New Direction for Higher Education (Vol. 53, pp. 147-169). San Francisco, CA: Jossey-Bass.

Bean, J. P., \& Bradley, R. K. (1986). Untangling the satisfaction-performance relationship for college students. The Journal of Higher Education, 393-412.

Beecher, M., \& Fischer, L. (1999). High School Courses and Scores as Predictors of College Success. Journal of College Admission, 163, 4-9.

Beller, M. (2001). Admission to higher education in Israel and the role of the Psychometric Entrance Test: Educational and political dilemmas. Assessment in Education: Principles, Policy \& Practice, 8(3), 315-337.

Bénabou, R., \& Tirole, J. (2003). Intrinsic and extrinsic motivation. The Review of Economic Studies, 70(3), 489-520.

Benneworth, P., De Boer, H., Cremonini, L., Jongbloed, b., Leisyte, L., Vossensteyn, H., \& De Weert, E. (2011). Quality-related funding, performance agreements and profiling in higher education. Enschede, The Netherlands: Center for Higher Education Policy Studies.

Bettinger, E., \& Baker, R. (2011). The effects of student coaching in college: An evaluation of a randomized experiment in student mentoring. Cambridge, England: National Bureau of Economic Research. 
Bitner, M. J., \& Hubbert, A. R. (1994). Encounter satisfaction versus overall satisfaction versus quality: the customer's voice. In R. T. Rust \& R. L. Oliver (Eds.), Service quality: New directions in theory and practice (pp. 72-94). Thousand Oaks, CA: Sage.

Broek, A. van den, Kurver, B., \& Hampsink, S. (2012). NSE 2011: Onderzoeksverantwoording. ResearchNed Nijmegen. Retrieved 16-08, from http://www.studiekeuzeinformatie.nl/wpcontent/uploads/2012/05/Onderzoeksverantwoording-NSE-2011.pdf

Bruinsma, M. (2004). Motivation, cognitive processing and achievement in higher education. Learning and instruction, 14(6), 549-568.

Bryant, J. L. (2006). Assessing expectations and perceptions of the campus experience: The NoelLevitz Student Satisfaction Inventory. New Directions for Community Colleges, 2006(134), 2535 .

Bound, J., Lovenheim, M. F., \& Turner, S. (2010). Why have college completion rates declined? An analysis of changing student preparation and collegiate resources. American economic journal. Applied economics, 2(3), 129.

Burke, J. C., \& Serban, A. M. (1997). Performance funding and budgeting for public higher education: Current status and future prospects. Albany, NY: The Nelson Rockefeller Institute of Government, State University of New York

Calcagno, J. C., Bailey, T., Jenkins, D., Kienzl, G., \& Leinbach, T. (2008). Community college student success: What institutional characteristics make a diderence? Economics of Education review, 27(6), 632-645.

Cambiano, R., Denny, G., \& DeVore, J. (2000). College Student Retention at a Midwestern University: A Six-Year Study. Journal of College Admission, 166, 22-29.

Chambers, S. R. (2009). Student engagement: using the NSSE benchmarks to investigate longterm persistence. Doctoral dissertation, Montana State University-Bozeman, College of Education, Health \& Human Development.

Chickering, A. W., \& Reisser, L. (1993). Education and Identity. San Francisco, CA: Jossey-Bass.

Cone, A. L., \& Owens, S. K. (1991). Academic and locus of control enhancement in a freshman study skills and college adjustment course.Psychological Reports, 68(3c), 1211-1217.

Cotton, S. J., Dollard, M. F., \& de Jonge, J. (2002). Stress and student job design: Satisfaction, wellbeing, and performance in university students. International Journal of Stress Management, 9(3), 147-162.

Cox, P., Schmitt, E., Bobrowski, P., \& Graham, G. (2005). Enhancing the first-year experience for business students: Student retention and academic success. Journal of Behavioral and Applied Management, 7(1), 40-68.

Davies, S. (2002). Marketing in higher education: Matching promises and reality to expectations. Responding to Student Expectations. Paris, France: OECD Publications.

Dehejia, R. H., \& Wahba, S. (2002). Propensity score-matching methods for nonexperimental causal studies. Review of Economics and statistics, 84(1), 151-161.

De Koning, B. B., Loyens, S. M. M., Rikers, R. M. J. P., Smeets, G., \& van der Molen, H. T. (2014). Impact of binding study advice on study behavior and pre-university education qualification factors in a problem-based psychology bachelor program. Studies in Higher Education,39(5), 113.

De Witte, K., Rogge, N., Cherchye, L. and Van Puyenbroeck, T. (2013), Accounting for economies of scope in performance evaluations of university professors. Journal of the Operational Research Society, 64(3), 1595-1606. 
Dill, D. D. (2001). The regulation of academic quality: critical issues in problem diagnosis and policy design. Paper presented at the Norwegian Institute for Studies in Research and Higher Education Oslo.

Duijndam, F. J., \& Scheepers, A. W. A. (2009). Bindend studieadvies [Academic dismissal policy]. Hoger Onderwijs Management, 1(5), 17-19.

Duncan-Hewitt, W. C. (1996). Designing admissions criteria: A framework. American Journal of Pharmaceutical Education, 60(2), 109-121.

Elliott, K. M. (2002). Key determinants of student satisfaction. Journal of College Student Retention: Research, Theory and Practice, 4(3), 271-279.

Elliott, K. M., \& Shin, D. (2002). Student satisfaction: An alternative approach to assessing this important concept. Journal of Higher Education Policy and Management, 24(2), 197-209.

Fike, D. S., \& Fike, R. (2008). Predictors of first-year student retention in the community college. Community College Review, 36(2), 68-88.

Forrest, A. (1982). Increasing Student Competence \& Persistence. Iowa City: Iowa: ACT National Center for the Advancement of Educational Practices.

Gijbels, D., Van der Rijt, J., \& Van de Watering, G. (2004). Het bindend studieadvies in het hoger wetenschappelijk onderwijs: worden de juiste studenten geselecteerd? [The binding study advice in higher scientific education: Are the right students selected?]. Tijdschrift voor Hoger Onderwijs, 22(2), 62-72.

Hagedorn, L. S., \& Nora, A. (1996). Rethinking admissions criteria in graduate and professional programs. New Directions for Institutional Research, 1996(92), 31-44.

Hollon, C. J, \& Chesser, R. J (1976). The relationship of personal influence dissonance to job tension, satisfaction and involvement. The Academy of Management Journal, 19(2), 308-314.

Huisman, J. (2008). Shifting boundaries in higher education: Dutch hogescholen on the move. In J. Taylor, J. B. Ferreira, M. De Lourdes Machado \& R. Santiago (Eds.), Non-university higher education in Europe (pp. 147-167): Springer.

Huisman, J., \& Currie, J. (2004). Accountability in higher education: Bridge over troubled water? Higher Education, 48(4), 529-551.

Hughes, R. \& Pace, C. R. (2003). Using NSSE to Study Student Retention and Withdrawal. Assessment Update, 15(4), 1-2.

Inspectie van het Onderwijs. (2010). Bindend Studieadvies: een landelijk beeld. Bijlage bij het rapport "Met beide benen op de grond. Onderzoek naar de uitvoeringspraktijk van het bindend studieadvies in het hoger onderwijs". Utrecht, The Netherlands: Inspectie van het Onderwijs.

Johnstone, D. B. (2004). The economics and politics of cost sharing in higher education: comparative perspectives. Economics of education review, 23(2004), 403-410.

Jongbloed, B. W. A., \& Koelman, J. B. J. (1996). Funding mechanisms for higher education: A fivecountry based survey with special reference to performance-based funding approaches. Enschede, the Netherlands: Center for Higher Education Policy Studies.

Jongbloed, B. W. A., Salerno, C., Huisman, J. (2004). Achtergrondstudie van de onderwijsraad. Enschede, Nederland: Center for Higher Education Policy Studies (CHEPS).

Jongbloed, B., \& Vossensteyn, H. (2001). Keeping up performances: an international survey of performance-based funding in higher education. Journal of Higher Education Policy and Management, 23(2), 127-145.

Kotler, P., \& Fox, K. F. (1995). Strategic marketing for educational institutions. Englewood Cliffs, NJ: Prentice Hall. 
Krohn, G. A., \& O'Connor, C. M. (2005). Student effort and performance over the semester. The Journal of Economic Education, 36(1), 3-28.

Kuh, G., Cruce, T., Shoup, R., Kinzie, J. \& Gonyea, R. (2008). Unmasking the effects of student engagement on first-fear college grades and persistence. The Journal of Higher Education, 79(5), 540-563.

Lau, L. K. (2003). Institutional factors adecting student retention. Education, 124(1), 126-136.

Leverett-Main, S. (2004). Program directors' perceptions of admission screening measures and indicators of student success. Counselor Education and Supervision, 43(3), 207-219.

Levitz, R. S., Noel, L., \& Richter, B. J. (1999). Strategic moves for retention success. In G. H. Gaither (Ed.), New directions for higher education: promising practices in recruitment, remediation , and retention (Vol. 1999, pp. 31-49). San Francisco, CA: Jossey-Bass.

Lindo, J. M., Sanders, N. J., \& Oreopoulos, P. (2010). Ability, Gender, and Performance Standards: Evidence from Academic Probation. American economic journal: Applied economics, 2(2), 95117.

McCracken, J. D., \& Barcinas, J. D. T. (1991). Differences between rural and urban schools, student characteristics, and student aspirations in Ohio. Journal of Research in Rural Education, 7(2), 29-40.

McNabb, R., Pal, S., \& Sloane, P. (2002). Gender differences in educational attainment: The case of university students in England and Wales. Economica, 69(275), 481-503.

Mellanby, J., Martin, M., \& O'Doherty, J. (2000). The 'gender gap' in final examination results at Oxford University. British Journal of Psychology, 91(3), 377-390.

Mennen, J. (2013). Laid-back of up-tempo? De voorspellende Kwaliteit van het Eerste jaar voor de Studievoortgang in een Conservatorium. Thesis, Open Universiteit. Retrieved at 06-04, 2014, from http://dspace.ou.nl/bitstream/1820/4803/1/OWJMennen-02012013.pdf

Miles, R. H. (1976). A Comparison of the Relative Impacts of Role Perceptions of Ambiguity and Conflict by Role. Academy of Management Journal, 19(1), 25-35.

Miller, R. (2003). Student satisfaction and institutional success. Paper presented at the 43rd annual AIR forum, Tampa, FL, May, 2003.

Moore, C., Offenstein, J., \& Shulock, N. (2009). Steps to success: Analyzing milestone achievement to improve community college student outcomes. Sacramento: California State University, Institute for Higher Education Leadership \& Policy.

NSSE (2013). A Fresh Look at Student Engagement-Annual Results 2013. Bloomington, IN: Indiana University Center for Postsecondary Research.

NVAO (n.d.) NVAO: Nederlands-Vlaamse accreditatieorganisatie. Retrieved 14-02, 2013, from http://www.nvao.net/over_nvao

OCW (2011). Hoofdlijnenakkoord OCW-VSNU. Retrieved at 24-10, 2013, from http://www.vsnu.nl/files/documenten/Domeinen/Accountability/HLA/Hoofdlijnenakkoord_unive rsiteiten_DEF_20111208.pdf

Okun, M. A., \& Finch, J. F. (1998). The big five personality dimensions and the process of institutional departure. Contemporary Educational Psychology,23(3), 233-256.

Onderwijs Evaluatie Rapport (2007). Bindend studieadvies. Een onderzoek naar de meningen en ervaringen van eerstejaars bachelorstudenten aan de Universiteit Utrecht. Retrieved at 25-07, 2014, from: http://stichting-oer.nl/wordpress/wp-content/uploads/2010/10/0607-bsa.pdf

Onderwijsraad. (2008). Een succesvolle start in het hoger onderwijs. Den Haag: Onderwijsraad.

Pantages, T. J., \& Creedon, C. F. (1978). Studies of college attrition: 1950-1975. Review of educational research, 48(1),49-101. 
Peikes, D. N., Moreno, L., \& Orzol, S. M. (2008). Propensity Score Matching. The American Statistician, 62(3), 222-231.

Peterson, M., Wagner, J. A., \& Lamb, C. W. (2001). The Role of Advising in Non-Returning Students' Perceptions of Their University. Journal of Marketing for Higher Education, 10(3), 4559.

Peltier, G. L., Laden, R., \& Matranga, M. (1999). Student persistence in college: A review of research. Journal of College Student Retention, 1(4), 357-375.

Porter, S. R. (2000). The robustness of the "graduation rate performance" indicator used in the U.S. News and World Report college ranking. International Journal of Educational Advancement 1(2), 10-30

Reason, R. D. (2003). Using an ACT-based merit-index to predict between-year retention. Journal of College Student Retention: Research, Theory and Practice, 5(1), 71-87.

Rijksoverheid. (n.d.) Wat is het binded studieadvies (BSA) in het hoger onderwijs (ho)? Retrieved 803, 2013, from http://www.rijksoverheid.nl/onderwerpen/hoger-onderwijs/vraag-enantwoord/wat-is-het-bindend-studieadvies-bsa-in-het-hoger-onderwijs-ho.html

Rienzi, B. M., Allen, M. J., Sarmiento, Y. Q., \& McMillin, J. D. (1993). Alumni perception of the impact of gender on their university experience. Journal of College Student Development, 34(2), 154-157.

Rosenbaum, P. R., \& Rubin, D. B. (1983). The central role of the propensity score in observational studies for causal effects. Biometrika, 70(1), 41-55.

Salvatori, P. (2001). Reliability and validity of admissions tools used to select students for the health professions. Advances in Health Sciences Education, 6(2), 159-175.

Schertzer, C. B., \& Schertzer, S. M. (2004). Student satisfaction and retention: A conceptual model. Journal of Marketing for Higher Education, 14(1), 79-91.

Scott, M., Bailey, T., \& Kienzl, G. (2006). Relative success? Determinants of college graduation rates in public and private colleges in the US. Research in higher education, 47(3), 249-279.

Scott, G., Shah, M., Grebennikov, L., \& Singh, H. (2008). Improving student retention: A University of Western Sydney case study. Journal of Institutional Research, 14(1), 9-23.Steenkamp, F., Timmers, T., \& van Schilt, J. (2008a). Jaarrapport Nationale Studentenenquête 2007. Leiden, The Netherlands: Centrum Hoger Onderwijs Informatie voor Consument en Expert.

Steenkamp, F., Timmers, T., van Schilt, J., Heim, M., \& de Goede, M. (2008b). Tien jaar patronen en trends in" student satisfaction" in Nederland: een analyse van oordelen uit de Keuzegidsenquête en de Nationale Studenten Enquête, 1996-2005. Leiden, the Netherlands: Centrum Hoger Onderwijs Informatie voor Consument en Expert.

Stegers-Jager, K. M., Cohen-Schotanus, J., Splinter, T. A. W., \& Themmen, A. P. N. (2011). Academic dismissal policy for medical students: effect on study progress and help-seeking behaviour. Medical education, 45(10), 987-994.

Studiekeuze123. (2012). Routeboek voor de Nationale Studentenenquête 2012. Retrieved 04/10, 2012, from http://www.studiekeuzeinformatie.nl/wp-content/uploads/2012/04/NSE_ ROUTEBOEK_2012_COMPLEET_DEF.pdf

Tan, K. C., \& Kek, S. W. (2004). Service quality in higher education using an enhanced SERVQUAL approach. Quality in Higher Education, 10(1), 17-24.

Task force studiesucces. (2009). Eindadvies studiesucces. Leiden, The Netherlands: Universiteit Leiden.

Tinto, V. (1975). Dropout from higher education: A theoretical synthesis of recent research. Review of educational research, 45(1), 89-125. 
Tinto, V. (1993). Leaving college: Rethinking the causes and cures of student attrition. Chicago, IL: The University of Chicago Press.

Tinto, V. (2002). Promoting student retention: Lessons learned from the United States. Paper presented at the 11th Annual Conference of the European Access Network, Prato, Italy.

Titus, M. A. (2004). An examination of the in.uence of institutional context on student persistence at 4-year colleges and universities: A multilevel approach. Research in Higher Education, 45(7), 673-699.

Tricker, T. (2005). Student expectations-how do we measure up. In F. MCMahon \& T. Cleas (Eds.), Probing the boundaries of higher education (pp. 111-114). Oxford, UK: Inter-Disciplinary Press.

Umbach, P. D., \& Porter, S. R. (2002). How do academic departments impact student satisfaction? Understanding the contextual effects of departments. Research in Higher Education, 43(2), 209234.

Van Heerden, A. (2013). Dropout and study progress in Higher Education. Hogeschool van Amsterdam - TIER, mimeo.

Wiers-Jenssen, J., Stensaker, B., \& Gr $\oslash$ gaard, J. B. (2002). Student satisfaction: towards an empirical deconstruction of the concept. Quality in Higher Education, 8(2), 183-195.

Yorke, M., \& Longden, B. (2004). Retention \& Student Success in Higher Education. Maidenhead, England: Open University Press. 


\section{Appendix A - Parallel time trend assumption}

Table 1: Common trend assumption when AD policy is introduced in 2005-06 for the different outcome variables

\begin{tabular}{|c|c|c|c|c|}
\hline Year & control group & $\begin{array}{c}\text { programs that eventually } \\
\text { will implement an AD } \\
\text { policy }\end{array}$ & t-statistic ${ }^{11}$ & p-value \\
\hline \multicolumn{5}{|c|}{ Student drop-out } \\
\hline \multirow[t]{2}{*}{ 2003-04 } & 17.67813 & 17.21000 & & \\
\hline & & & -0.50980 & 0.303090 \\
\hline 2004-05 & 16.22152 & 18.28000 & & \\
\hline \multicolumn{5}{|c|}{ Student graduation } \\
\hline \multirow[t]{2}{*}{ 2003-04 } & 52.17097 & 68.85000 & & \\
\hline & & & 0.52022 & 0.60380 \\
\hline 2004-05 & 51.01867 & 64.28000 & & \\
\hline \multicolumn{5}{|c|}{ Overall satisfaction } \\
\hline \multirow[t]{2}{*}{ 2003-04 } & 7.70232 & 7.61847 & & \\
\hline & & & 0.61855 & 0.53700 \\
\hline 2004-05 & 7.64664 & 7.67334 & & \\
\hline \multicolumn{5}{|c|}{ Average NSE score } \\
\hline \multirow[t]{2}{*}{ 2003-04 } & 7.04701 & 6.923773 & & \\
\hline & & & 5.62012 & .00000 \\
\hline 2004-05 & 7.05591 & 6.725286 & & \\
\hline \multicolumn{5}{|c|}{ Satisfaction concerning program feasibility } \\
\hline \multirow[t]{2}{*}{ 2003-04 } & 6.60035 & 7.04879 & & \\
\hline & & & -0.5499 & 0.58300 \\
\hline 2004-05 & 6.56483 & 7.08615 & & \\
\hline
\end{tabular}

Table 2: Common trend assumption when AD policy is introduced in 2007-08 for the different outcome variables

\begin{tabular}{|c|c|c|c|c|}
\hline Year & control group & $\begin{array}{c}\text { programs that } \\
\text { eventually will } \\
\text { implement an AD policy }\end{array}$ & t-statistic & $p$-value \\
\hline \multicolumn{5}{|c|}{ Student dropout } \\
\hline \multirow[t]{2}{*}{$2003-04$} & 17.67813 & 16.32500 & & \\
\hline & & & -0.19796 & 0.8434 \\
\hline \multirow[t]{2}{*}{ 2004-05 } & 16.22152 & 15.85455 & & \\
\hline & & & -0.04308 & 0.9657 \\
\hline \multirow[t]{2}{*}{ 2005-06 } & 18.58819 & 18.39565 & & \\
\hline & & & -0.24204 & 0.8089 \\
\hline $2006-07$ & 17.87905 & 18.74783 & & \\
\hline \multicolumn{5}{|c|}{ Student graduation } \\
\hline \multirow[t]{2}{*}{ 2003-04 } & 52.10970 & 69.46250 & & \\
\hline & & & 0.15009 & 0.8794 \\
\hline \multirow[t]{2}{*}{ 2004-05 } & 51.01867 & 66.12727 & & \\
\hline & & & -0.19605 & 0.8447 \\
\hline \multirow[t]{2}{*}{ 2005-06 } & 50.84823 & 67.92174 & & \\
\hline & & & 0.06964 & 0.9445 \\
\hline 2006-07 & 52.93219 & 69.41739 & & \\
\hline
\end{tabular}

${ }^{11}$ This t-statistic between four groups is estimated by applying the next formulas:

1) T-test $=$ difference/s.e. $\left[\left(\bar{Y}_{2}-\bar{Y}_{4}\right)-\left(\overline{Y_{1}}-\overline{Y_{3}}\right)\right]$

2) Difference $=\left(\bar{Y}_{2}-\bar{Y}_{4}\right)-\left(\bar{Y}_{1}-\bar{Y}_{3}\right)$

3) s.e. $\left[\left(\overline{Y_{2}}-\overline{Y_{4}}\right)-\left(\overline{Y_{1}}-\overline{Y_{3}}\right)\right]=\sqrt{\left(\left[\frac{s_{2}^{2}}{n_{2}}\right]+\left[\frac{s_{4}^{2}}{n_{4}}\right]\right)+\left(\left[\frac{s_{1}^{2}}{n_{1}}\right]+\left[\frac{s_{3}^{2}}{n_{3}}\right]\right)}$ 


\begin{tabular}{|c|c|c|c|c|}
\hline \multicolumn{5}{|c|}{ Overall satisfaction } \\
\hline $2003-04$ & 7.70232 & 7.67035 & & \\
\hline & & & -1.2842 & 0.2008 \\
\hline \multirow[t]{2}{*}{$2004-05$} & 7.64664 & 7.85334 & & \\
\hline & & & 0.53296 & 0.5944 \\
\hline \multirow[t]{2}{*}{$2005-06$} & 7.47936 & 7.58980 & & \\
\hline & & & 2.26184 & 0.0422 \\
\hline $2006-07$ & 7.32302 & 7.19212 & & \\
\hline \multicolumn{5}{|c|}{ Average NSE score } \\
\hline \multirow[t]{2}{*}{ 2003-04 } & 7.04589 & 7.01980 & & \\
\hline & & & -1.21106 & 0.2267 \\
\hline \multirow[t]{2}{*}{$2004-05$} & 7.05591 & 7.08703 & & \\
\hline & & & -0.80549 & 0.4209 \\
\hline \multirow[t]{2}{*}{$2005-06$} & 7.09764 & 7.17026 & & \\
\hline & & & 1.74649 & 0.0814 \\
\hline $2006-07$ & 6.97333 & 6.92591 & & \\
\hline \multicolumn{5}{|c|}{ Satisfaction concerning program feasibility } \\
\hline \multirow[t]{2}{*}{$2003-04$} & 6.60035 & 6.84051 & & \\
\hline & & & -3.16656 & 0.0018 \\
\hline \multirow[t]{2}{*}{ 2004-05 } & 6.56483 & 7.44475 & & \\
\hline & & & 2.21044 & 0.0290 \\
\hline \multirow[t]{2}{*}{$2005-06$} & 6.41611 & 6.87112 & & \\
\hline & & & -1.01641 & 0.3112 \\
\hline 2006-07 & 6.522684 & 7.17342 & & \\
\hline
\end{tabular}

Table 3: Common trend assumption when AD policy is introduced in 2008-09 for the different outcome variables

\begin{tabular}{|c|c|c|c|c|}
\hline Year & control group & $\begin{array}{c}\text { programs that } \\
\text { eventually will } \\
\text { implement an } A D \text { policy }\end{array}$ & t-statistic & $\mathrm{p}$-value \\
\hline \multicolumn{5}{|c|}{ Student drop-out } \\
\hline \multirow[t]{2}{*}{ 2003-04 } & 17.67813 & 20.450000 & & \\
\hline & & & 0.03220 & 0.9744 \\
\hline \multirow[t]{2}{*}{ 2004-05 } & 16.22152 & 18.850000 & & \\
\hline & & & 0.26298 & 0.7928 \\
\hline \multirow[t]{2}{*}{ 2005-06 } & 18.58819 & 20.44146 & & \\
\hline & & & 0.18084 & 0.8566 \\
\hline \multirow[t]{2}{*}{ 2006-07 } & 17.87905 & 19.26667 & & \\
\hline & & & -0.88230 & 0.3783 \\
\hline $2007-08$ & 16.09327 & 19.79394 & & \\
\hline \multicolumn{5}{|c|}{ Student graduation } \\
\hline \multirow[t]{2}{*}{ 2003-04 } & 52.17097 & 43.85000 & & \\
\hline & & & -1.35663 & 0.1773 \\
\hline \multirow[t]{2}{*}{ 2004-05 } & 51.01867 & 52.40000 & & \\
\hline & & & -0.07172 & 0.9429 \\
\hline \multirow[t]{2}{*}{ 2005-06 } & 50.84823 & 52.61220 & & \\
\hline & & & -0.16194 & 0.8714 \\
\hline \multirow[t]{2}{*}{ 2006-07 } & 52.93219 & 55.49524 & & \\
\hline & & & -0.10224 & -0.9186 \\
\hline 2007-08 & 49.88750 & 53.00303 & & \\
\hline
\end{tabular}




\begin{tabular}{|c|c|c|c|c|}
\hline \multicolumn{5}{|c|}{ Overall satisfaction } \\
\hline 2003-04 & 7.70232 & 7.83066 & & \\
\hline & & & 1.01004 & 0.3138 \\
\hline \multirow[t]{2}{*}{$2004-05$} & 7.64664 & 7.61804 & & \\
\hline & & & -0.84056 & 0.4012 \\
\hline \multirow[t]{2}{*}{$2005-06$} & 7.47936 & 7.52537 & & \\
\hline & & & -2.69522 & 0.0073 \\
\hline \multirow[t]{2}{*}{$2006-07$} & 7.32302 & 7.56727 & & \\
\hline & & & 0.8829 & 0.3785 \\
\hline $2007-08$ & 7.50859 & 7.64113 & & \\
\hline \multicolumn{5}{|c|}{ Average NSE score } \\
\hline \multirow[t]{2}{*}{ 2003-04 } & 7.04589 & 7.11589 & & \\
\hline & & & -0.09305 & 0.9260 \\
\hline \multirow[t]{2}{*}{ 2004-05 } & 7.05591 & 7.13176 & & \\
\hline & & & 1.06529 & 0.2876 \\
\hline \multirow[t]{2}{*}{ 2005-06 } & 7.09763 & 7.10654 & & \\
\hline & & & -1.91691 & 0.05587 \\
\hline \multirow[t]{2}{*}{ 2006-07 } & 6.97333 & 7.11824 & & \\
\hline & & & 2.78928 & 0.0057 \\
\hline 2007-08 & 7.11595 & 7.01874 & & \\
\hline \multicolumn{5}{|c|}{ Satisfaction concerning program feasibility } \\
\hline \multirow[t]{2}{*}{ 2003-04 } & 6.60035 & 6.46962 & & \\
\hline & & & -0.32416 & 0.7462 \\
\hline \multirow[t]{2}{*}{ 2004-05 } & 6.56483 & 6.52854 & & \\
\hline & & & 0.98012 & 0.3290 \\
\hline \multirow[t]{2}{*}{ 2005-06 } & 6.41611 & 6.13018 & & \\
\hline & & & -0.43661 & 0.6631 \\
\hline \multirow[t]{2}{*}{ 2006-07 } & 6.52268 & 6.36784 & & \\
\hline & & & -0.34304 & 0.7320 \\
\hline $2007-08$ & 6.45324 & 6.40105 & & \\
\hline
\end{tabular}



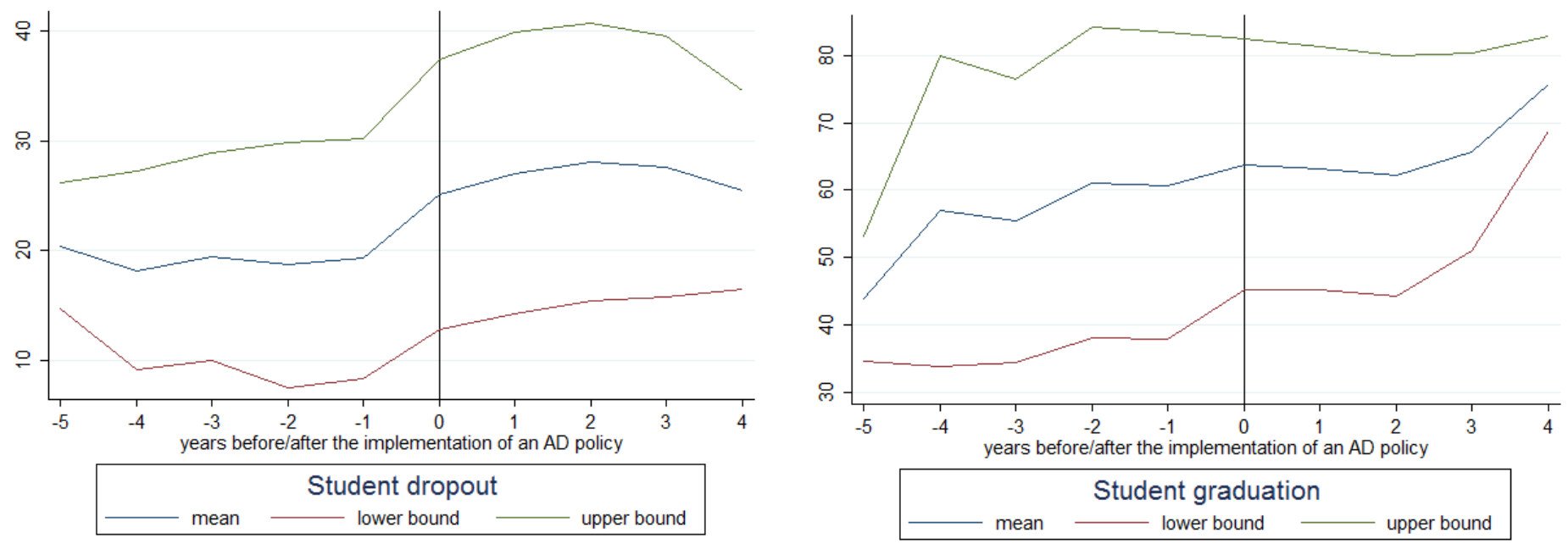

Figure 1 (left): Trend of student dropout before (negative numbers) and after (positive numbers) the introduction of an AD policy

Figure 2 (right) Trend of student graduation before (negative numbers) and after (positive numbers) the introduction of an AD policy
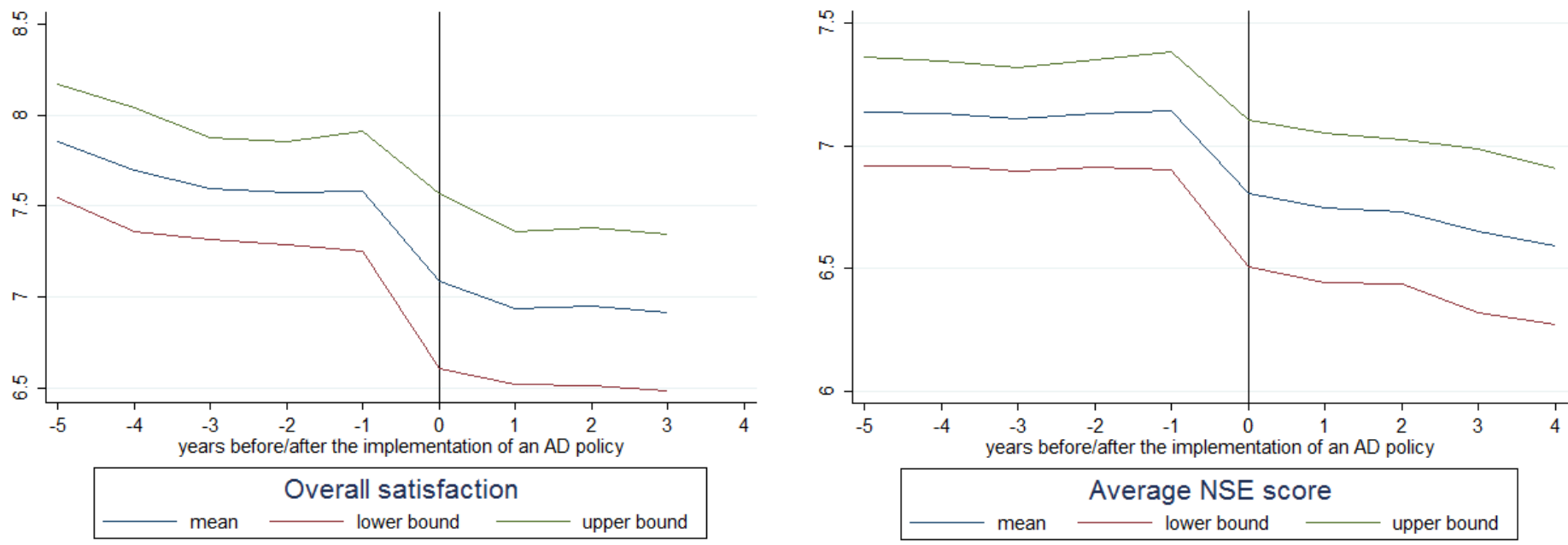

Figure 3 (left): Trend of overall student satisfaction of bachelor's students before (negative numbers) and after (positive numbers) the introduction of an AD policy Figure 4 (right) Trend of average NSE score of bachelor's students before (negative numbers) and after (positive numbers) the introduction of an AD policy 


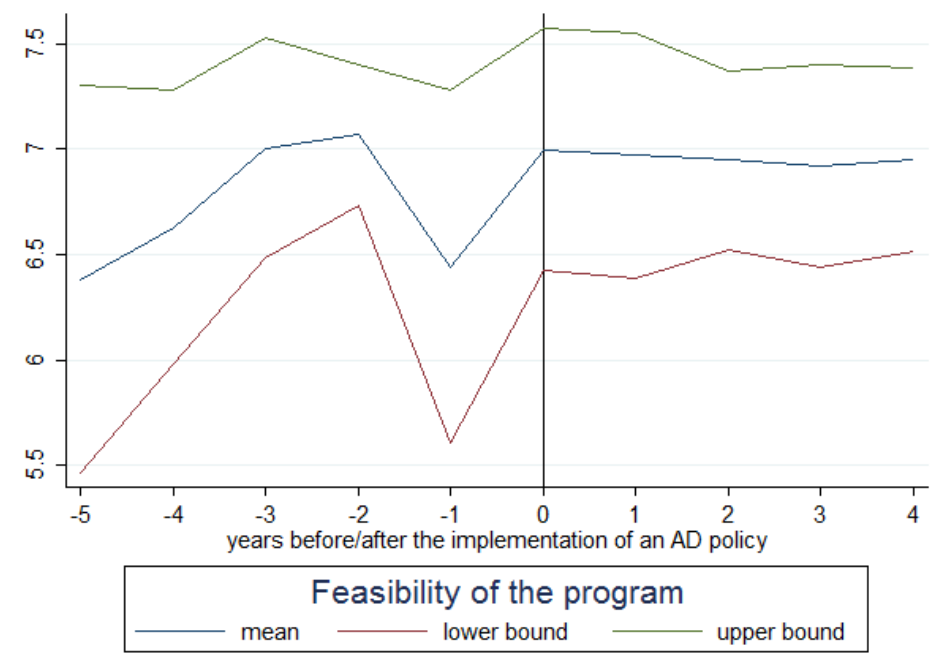

Figure 5: Trend of feasibility of the program perceived by bachelor's students before (negative numbers) and after (positive numbers) the introduction of an AD policy 